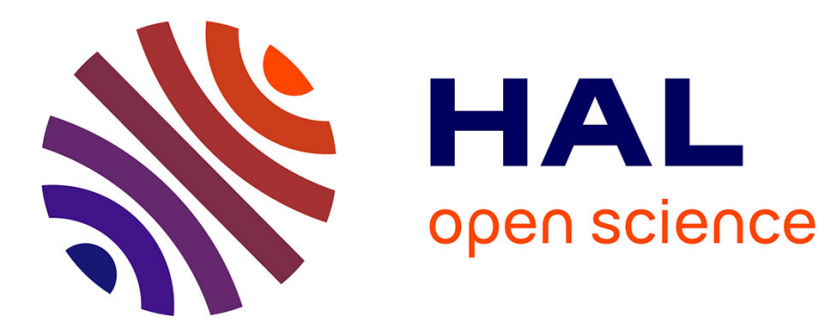

\title{
Une famille châtelaine sur les confins normanno-manceaux : les Géré (Xe-XIIIe s.) \\ Pierre Bauduin
}

\section{To cite this version:}

Pierre Bauduin. Une famille châtelaine sur les confins normanno-manceaux: les Géré (Xe-XIIIe s.). Archéologie médiévale, 1992, XXII, 10.3406/arcme.1992.1009 . hal-02560381

\section{HAL Id: hal-02560381}

https://hal-normandie-univ.archives-ouvertes.fr/hal-02560381

Submitted on 1 May 2020

HAL is a multi-disciplinary open access archive for the deposit and dissemination of scientific research documents, whether they are published or not. The documents may come from teaching and research institutions in France or abroad, or from public or private research centers.
L'archive ouverte pluridisciplinaire $\mathbf{H A L}$, est destinée au dépôt et à la diffusion de documents scientifiques de niveau recherche, publiés ou non, émanant des établissements d'enseignement et de recherche français ou étrangers, des laboratoires publics ou privés. 


\section{Une famille châtelaine sur les confins normanno-manceaux : les} Géré (Xe-XIIle s.)

\section{Pierre Bauduin}

\section{Citer ce document / Cite this document :}

Bauduin Pierre. Une famille châtelaine sur les confins normanno-manceaux : les Géré (Xe-XIIle S.). In: Archéologie médiévale, tome 22, 1992. pp. 309-356;

doi : https://doi.org/10.3406/arcme.1992.1009

https://www.persee.fr/doc/arcme_0153-9337_1992_num_22_1_1009

Fichier pdf généré le 15/03/2019 


\title{
Résumé
}

Apparus au Xe siècle, les Géré entrent au service des Bellême et contribuent à la mise en place de leur seigneurie le long de la dorsale forestière qui s'étend du Perche au Domfrontais. Grâce à l'appui de leur seigneur, les Géré obtiennent du duc de Normandie les seigneuries d'Echauffour et de Montreuil-l'Argillé, en pays d'Ouche. Devenus châtelains, ils s'émancipent de la tutelle des Bellême et tente de bâtir une puissance territoriale en pays d'Ouche et autour de Saint-Ceneri. L'apogée de cette première seigneurie se situe au milieu du Xle siècle avec la fondation de l'abbaye de Saint-Evroul. La reprise en main des confins normanno-manceaux par Guillaume le Conquérant rompt brutalement l'expansion des Géré. Le lignage, évincé de Normandie, retrouve ses possessions entre 1088 et 1119. Jusqu'à leur extinction en 1294, les barons de Saint-Ceneri n'eurent désormais qu'un rôle effacé. La tentative des Géré s'est appuyée sur la possession d'un ensemble de forteresses. Aux enceintes attestées dès le début du Xle siècle (Echauffour, Montreuil) s'ajoutent le château, peut-être de type angevin, de Saint-Ceneri, l'éperon barré de Montaigu et les enceintes de la Roche d'Igé. Cette maîtrise du sol s'accompagne de la création de bourgs castraux. Les barons de Saint-Ceneri étaient entourés d'un groupe aristocratique d'une vingtaine de lignages. Les sources en provenance de Saint-Evroul permettent d'en suivre quelques-uns et contribuent à mieux cerner les contours du groupe des milites à l'époque féodale.

\begin{abstract}
First appearing in the Xth century, the family of Géré enter into the service of the Bellême family, and contribute in setting up their lordship along the forest ridge which stretches from the Perch to the Domfrontais. Due to the influence of their Lord, the Géré obtained the lordships of Echauffour and Montreuil-l'Argillé, in the Pays d'Auge, from the Duke of Normandie. Having become Lords themselves, they emancipate themselves from the protec $\urcorner$ tion of the Bellême, and attempt to build a territorial power in the Pays d'Ouche and around Saint-Ceneri. The heyday of this first lordship is situated at the middle of the XIth century, with the foundation of the Saint-Evroul Abbey. The taking in hand of the normanno-manceaux borders by William the Conquerer brutally puts an end to the expansion of the Géré. Thrown out of Normandy, the lineage recuperate their possessions between 1088 and 1119. Until the family die out in 1294, the barons of Saint-Ceneri retain but an unobtrusive role.

The Géré family's attempt relied upon the possession of a group of fortresses. To those fortifications attested as early as the beginning of the XIth century (Echauffour, Montreuil) can be added the SaintCeneri castle, perhaps of Angevin type, the defended spur at Montaigu and the fortifications of the Roche d'Igé. This territorial control is accompanied by the creation of castle boroughs. The SaintCeneri barons were supported by an aristocratic group composed of about twenty lineages. The sources of information from Saint-Evroul allow us to follow some of these, and help to define the contours of a milites group of the feudal period.
\end{abstract}

\section{Zusammenfassung}

Das Geschlecht der Géré, im X. Jh. in Erscheinung getreten, tritt in den Dienst der Bellême und trâgt zur Stabilisierung ihres Herrschaftsgebietes lângs des bewaldeten Bergriickens bei, der sich vom Perche bis zur Gegend von Domfront erstreckt. Dank der Unterstutzung ihres Lehnsherrn erhalten sie vom Herzog der Normandie die Lehnsherrschaf-ten Echauffour und Montreuil-l'Argillé im Pays d'Ouche. Nachdem sie Burgherren geworden sind, befreien sie sich von der Lehnsherrschaft der Bellême und versuchen eine Terri torial-herrschaft um Saint-Cénéri im Pays d'Ouche zu errichten. Der Hôhepunkt dieser ersten Herrschaft fâllt in die Mitte des XI. Jh. mit der Grundung der Abtei SaintEvroul. Die Wiedereroberung der Grenzgebiete Normandie-Maine durch Wihlhelm den Eroberer unterbricht jàh die Ausbreitung der Géré ; sie werden aus der Normandie vertrieben und erlangen ihre Besitzungen erst zwischen 1088 und 1119 zurùck. Von nun an bis zu ihrem Aussterben im Jahre 1294 spielen die Barone von Saint-Cénéri lediglich eine untergeordnete Rolle. Der Machtentfaltungsversuch der Géré stutzte sich auf den Besitz einer ganzen Reihe von Befestigungsanlagen. Bereits Anfang des XI. Jh. sind die Ringmauern von Echauffour und Montreuil bezeugt, zu welchen die vielleicht nach der Anjouer Bauweise errichtete Burg von Saint-Cénéri, der verriegelte Bergsporn von Montaigu sowie die Ringmauern von la Roche d'Igé hinzukommen. Diese Herrschaft uber das Territorium hat die Grundung von befestigten Marktflecken im Gefolge. Ûbrigens 
waren die Barone von Saint-Cénéri von etwa zwanzig Adelgeschlechtern umgeben. Die Schriftquellen aus Saint-Evroul erlauben es uns, die Spuren einiger Familien zu verfolgen und dazu beizutragen, die Konturen dieser «Milites » zur Zeit der Feudalherrschaft besser zu umreiBen. 


\section{Une famille châtelaine sur les confins normanno-manceaux : les Géré ( $\mathrm{X}^{\mathrm{e}}-\mathrm{XIII}{ }^{\mathrm{e}} \mathrm{s}$.)}

L'intérêt porté aux Géré n'est pas nouveau, il s'explique en partie par les traces que le lignage a laissées dans la région où il vécut. Cette mémoire est visible à travers la toponymie puisque les Géré ont donné leur nom à la paroisse qui fut le chef de leur baronnie : Saint-Céneri-le-Gérei. Visible également à travers la topographie puisqu'il existe une rue des Giroie à Saint-Céneri ; ainsi qu'une rue Giroye à Alençon. Ces traces, ces souvenirs ont été repris, vivifiés par des historiens et des érudits locaux tels que l'abbé Persignan au XIX ${ }^{\mathrm{e}}$ siècle et plus récemment Monsieur H. Pastoureau (1). D'autre part, qui s'intéresse au principal lignage de l'Alençonnais, les Bellême, se trouve amené à évoquer les Géré, principaux concurrents des Bellême dans la région ; ce fut le cas d'Odolans Desnos à la fin du XVIII ${ }^{\mathrm{e}}$ siècle et tout récemment de Gérard Louise (2).

Ces traces qu'ont laissées les Géré dans les mémoires, nous les devons en partie à Orderic Vital (3). Sans l'auteur de l'Histoire ecclésiastique, avant 1050, nous ne saurions pas grand chose du lignage. Orderic Vital était bien informé : moine à Saint-Evroul, abbaye fondée par Guillaume Giroie, Hugues et Robert de Grand-

(1) Abbé Persignan, Saint-Cénéri-le-Gérei, ses souvenirs, ses monuments, Le Mans, 1865 ; H. Pastoureau, Histoire de Saint-Cénéri-le-Géréi. Le château de Saint-Cénéri : première époque les Giroie (1040-1294). Bulletin de la Société Historique et Archéologique de l'Orne, t. 85, 1967, pp. 3-65.

(2) O. Desnos, Mémoires historiques sur la ville d'Alençon et sur ses seigneurs. Alençon 1787 ; G. LouISE, Les confins de la Normandie et du Maine ( $X^{2}-X I I^{2}$ s.). La seigneurie de Bellême, étude historique et Archéologique. Thèse de doctorat d'Etat sous la direction de Monsieur A. Debord soutenue à Caen en novembre 1988.

(3) Orderic Vital, Historia ecclesiastica, ed. Chibnall, 6 vol., 1973-1980. 
mesnil ainsi que leurs proches, il était bien placé pour recueillir les témoignages sur les Géré, d'autant plus qu'un membre du lignage, Renaud, petit-fils de Guillaume Giroie fut aussi moine à Saint-Evroul. Mais ses informations sont à prendre avec précaution car Orderic n'est pas neutre: il prend résolument parti pour les fondateurs de Saint-Evroul et contient mal une rancune tenace contre les Bellême. Par ailleurs, le passage de l'Histoire ecclésiastique consacré aux Géré avant leur éviction du duché de Normandie est probablement contemporain de la restitution des seigneuries d'Echauffour et de Montreuil-l'Argillé à Robert II Giroie; il n'est pas impossible que le moine de Saint-Evroul l'ait « orientée » pour légitimer la restitution de ces deux seigneuries un demi-siècle après l'exil des Géré. Ces précautions prises, Orderic reste une source capitale, avec les archives de Saint-Evroul.

Comment situer les Géré dans l'aristocratie normande ? Lucien Musset a abordé la question en posant le problème des origines de cette aristocratie. Une première mise au point a été faite par J.M. Maillefer en 1985 (4). Le présent article se propose d'envisager les Géré et leurs possessions sous trois angles. Il s'agira tout d'abord de s'interroger sur les origines du lignage et la mise en place de la baronnie de Saint-Céneri en insistant sur l'aspect qui fait l'originalité de la tentative des Géré : la construction d'une seigneurie frontalière, aux confins de la Normandie et du Maine. Tous les aspects de cette seigneurie ne pouvant être abordés ici, nous insisterons dans un deuxième temps sur les châteaux et les bourgs, principaux instruments sur lesquels s'appuie la maîtrise du sol et des hommes. Toujours dans le cadre de la baronnie de Saint-Céneri, nous approcherons dans un dernier temps, un groupe encore peu étudié en Normandie : la petite aristocratie (5).

\section{LES GÉRÉ? UN LIGNAGE IMPLANTÉ EN MARCHE}

L'histoire des Géré est celle d'une tentative visant à profiter des incertitudes de la frontière méridionale de la Normandie, en particulier sur ses confins manceaux, pour construire une puissance châtelaine.

(4) L. MUSSET, L’aristocratic Normande au XI ${ }^{\mathrm{e}}$ siècle, dans la noblesse du Moyen Age. Essais à la mémoire de R. Boutruche, Paris, 1976. pp. 71-96; J.M. MAILLEFER, Une famille aristocratique aux confins de la Normandie : les Géré au XI ${ }^{\circ}$ siecle, Cahier des Annales de Normandie $n^{\prime \prime} 17$, Caen, 1985.

(5) Les Géré, harons de Saint-Cénéri: étude d'une famille châtelaine et de ses possessions $X^{*}-$ $X V^{\prime \prime}$ siècles, mémoire de maîtrise sous la direction de M.A. Debord, Caen, 1985. 


\section{Origine et implantation du lignage}

\section{a) L'origine du lignage}

C'est à Orderic Vital que nous devons les quelques indices concernant l'origine des Géré : Hic (Giroie I ${ }^{\mathrm{er}}$ ) ex magna nobilitate Francorum et Britonum processit (6). Plusieurs faits semblent confirmer cette double origine franque et bretonne. Nous savons en effet que le premier membre connu du lignage portait le nom d'Abbon le Breton. Par ailleurs, on remarque que plusieurs lignages où le nom de Giroie est attesté au XI ${ }^{\mathrm{e}}$ siècle sont, soit installés en Bretagne, près de Rennes, c'est le cas des seigneurs de Châteaugiron descendant de Giro Ansquetilli filius, soit d'origine bretonne, comme les seigneurs de Beaupréau en Anjou, dont le premier ancêtre connu est Josselin de Rennes (7). Dans les deux cas, le berceau de la famille est le comté de Rennes, peut-être était-ce le cas des Géré. L'ascendance franque semble attestée par l'anthoponymie, Giroie (Geroius, que l'on trouve aussi sous les formes Giroius, Gerogius, Girois ; Géré en est la forme romane) est à rapprocher des noms d'origine franque en Géro ou Géri - cette forme est attestée dès le IX ${ }^{\mathrm{e}}$ siècle en Champagne dans le polyptyque de Reims - et du scandinave Geiri tiré des substantifs Geirr (pique, javelot) (8). D'après J.M. Maillefer, la plupart des membres $\mathrm{du}$ lignage portent des prénoms typiquement germaniques.

Orderic Vital indique que Giroie $\mathrm{I}^{\mathrm{er}}$ " mena une vie pleine de vertu et de courage quand Hugues le Grand (sic) et Robert étaient rois de France ». Le champ d'action des lignages portant un anthroponyme Gero/Geri semble d'abord avoir été le territoire de la France situé entre la Loire et la Seine et qu'ils aient été présents dans l'entourage des Robertiens. Les Géré furent sans doute installés dès le $\mathrm{X}^{\mathrm{e}}$ siècle en pays Chartrain et en Corbonnais, c'est dans ces deux régions en effet que l'on retrouve deux lignages apparentés aux Géré. Orderic Vital nous signale l'existence en Corbonnais d'un chevalier nommé Guy Bollein pronepos et cognatus de Robert de Grandmesnil (abbé de Saint-Evroul), fils de Robert de Grandmesnil et d'Hadvis Géré (9). Ce Guy Bollein apparaît comme témoin dans un acte de 1058 avec un autre personnage proche du restaurateur de Saint-Evroul, Yves ${ }^{\text {er }}$ de Courville. Les sires de Courville sont étroitement liés aux Géré : c'est à Courville qu'Ernaud d'Echauffour, exilé par Guillaume le Conquérant trouve refuge cum Geroio ejusdem oppidi dominus cujus propinquus et amicus erat. Par ailleurs certains noms (Giroie, Hildiarde) sont communs aux deux lignages (10).

(6) Orderic VITAL, op. cit., note 3, II, 22.

(7) J.M. MAILleFER, op. cit., note 4, pp. 176-177; O. Guillot, Le Comte d'Anjou et son entourage au $X f^{?}$ siècle, Paris 1972, pp. 298-300.

(8) J. Adigard Des Gautries, Les noms de personnes scandinaves en Normandie 911-1066, Lund, 1954, pp. 206-207.

(9) Orderic VITAL, op. cit., note 3, II, 77.

(10) Ibidem II, 107-108; A. CHEDEville, Chartres et ses campagnes $X f^{r}-X I I t^{\prime}$ siècles, Paris, 1973. 
Au total, il semble qu'on puisse retenir les informations d'Orderic Vital quant aux origines des Géré, lignage ayant des ascendances franque et bretonne gravitant peut-être dans l'entourage des Robertiens (on trouve en effet un Girous Miles dans une charte en faveur de Saint-Julien de Tours, souscrite entre autres par Hugues duc des Francs, vers 978/83). Au XI siècle plusieurs personnages portant le nom de Gerogius apparaissent dans les actes de Philippe $\mathrm{I}^{\mathrm{er}}(11)$ exerçant surtout entre Seine et Loire. C'est ce que confirme l'implantation du lignage.

\section{b) Les Géré en Corbonnais}

Les Géré apparaissent d'abord implantés à Courcerault dans le pagus du Corbonnais où vivait Ernaldus le Gros, père de Giroie ${ }^{\mathrm{er}}$, sans doute dans la seconde moitié du $\mathrm{X}^{\mathrm{e}}$ siècle. Cette implantation appelle plusieurs remarques. Tout d'abord, elle est contemporaine de l'apparition de la seigneurie de Bellême qui prit naissance dans la deuxième partie du $\mathrm{X}^{\mathrm{e}}$ siècle, probablement lors de la désagrégation de l'ancien comté carolingien du Corbonnais vers l'An Mil (12). Pour G. Louise celle-ci est contemporaine de l'implantation de la dynastie capétienne et apparaît comme une des dernières fenêtres que conserve le nouveau roi autour de son domaine. Or, nous avons vu plus haut que plusieurs personnages portant l'anthroponyme Gero gravitaient dans l'entourage des Robertiens. Même si les liens entre ces personnages et les Géré ne sont pas prouvés, on peut se demander si l'implantation du lignage en Corbonnais ne ressort pas des mêmes motifs que ceux qui présidèrent à la naissance de la seigneurie de Bellême. On ne sait comment Courcerault échut à Ernaldus, il faut remarquer cependant que Courcerault est un ancien domaine de Saint-Germain-desPrés. Or au $\mathrm{X}^{\mathrm{e}}$ siècle les Robertiens, abbés laïcs de Saint-Germain-des-Prés n'hésitent pas à dilapider le temporel de l'abbaye pour s'assurer de la fidélité de tel vassal et consolider leur implantation dans une région donnée (13).

Si ténus soient ces éléments, on peut se demander si l'implantation des Géré en Corbonnais ne relève pas de la volonté chez les Robertiens de consolider leur position dans un secteur qui constitue une pointe avancée tournée contre les comtés du Maine, de Chartres et le duc de Normandie (14). Cette hypothèse, si elle se confirmait, expliquerait du même coup l'apparition des Géré dans l'entourage des Bellême.

(11) Fragments de chartes $d u$ XI siècle provenant de Saint-Julien de Tours, ed. M. Ch. de Grandmaison, Pairs 1886, $\mathrm{n}^{\circ}$ XXVII. Recueil des Actes de Philippe $I^{e r}$, ed. M. Prou, Paris, 1906, p. 21, p. 187.

(12) G. LouISE, op. cit., note 2, p. 585.

(13) A. Longon, Polyptyque de l'abbaye de St-Germain des Prés rédigé au temps de l'abbé Irminon, Paris, 1886-1895 ; t. II, pp. 168-169 ; Y. SASSIER, Hugues Capet, Paris, 1987, p. 128.

(14) G. Louise, op. cit., note 12. 


\section{c) Au service des Bellême}

Ces liens avec les Bellême sont clairement établis à la génération suivante où Giroie $\mathrm{I}^{\mathrm{er}}$ intervient aux côtés de Guillaume $\mathrm{I}^{\mathrm{er}}$ de Bellême, dans un combat qui l'opposait au comte du Maine Herbert Fveille Chien : " quand Guillaume et les siens furent vaincus et mis en fuite, Giroie résista fermement jusqu'à ce qu'Herbert et ses troupes s'enfuient, remportant une victoire dont ceux qui en ont connaissance aujourd'hui font toujours l'éloge (15)».

Le combat prend place entre 1015 et 1025 , au moment où la seigneurie de Bellême consolide son expansion dans le Maine. Il est probable que dès cette époque Giroie I ${ }^{\text {er }}$ était vassal des Bellême. O. Vital nous apprend en effet que vers 1020 Giroie possédait l'église de Saint-Martin de Hauterive. Il tenait vraisemblablement Hauterive des Bellême. C'est peut-être à cette époque ( $1^{\mathrm{er}}$ quart du XI $\mathrm{CI}^{\mathrm{c}} \mathrm{s}$.) qu'il faut aussi faire remonter l'implantation des Gére à Radon, cette implantation autour de Hauterive et Radon jalonnant les progrès de la seigneurie des Bellême le long de la dorsale forestière s'étendant du Mortinais au Perche et au Chartrain, notamment en Hiémois (16).

\section{La construction de la première seigneurie des Géré (vers 1015-1050)}

\section{a) Giroie $I^{\text {er }}$, vassal du duc de Normandie}

Jusque vers 1015 , les Géré firent carrière en dehors de la Normandie. Orderic Vital nous relate les circonstances de leur implantation dans le duché : «Un puissant chevalier nommé Heugon (Helgo) offrit en mariage à Giroie sa fille unique, avec Montreuil et Echauffour et les terres dépendantes de ces deux oppida en dot. Quand Heugon mourut, peu après, Giroie entra en possession de tous ses fiefs, mais la jeune fille qui lui était destinée mourut de mort prématurée avant le mariage. Ensuite Guillaume de Bellême cmmena Giroie chez Richard, duc de Normandie, à Rouen, et le duc généreux reconnaissant sa valeur, accéda à sa demande et lui concéda les terres d'Heugon à tenir par droit héréditaire (jure hereditario) (17). Nous ne nous attarderons pas sur les circonstances de l'établissement de Giroie en Normandie (Heugon lui aurait offert en mariage sa fille); G. Duby a montré que la conquête

(15) Orderic VITAL, op. cit., note 3, II, 23.

(16) Ibidem II, 24 ; La charte de fondation de Saint-Evroul (M. FAurouX, L. MuSSET, Recueil des Actes des ducs de Normandie, Caen, 1961, $\mathrm{n}^{\circ}$ 122) mentionne l'église de Radon parmi les dons des Géré ; G. LOUISE, $o p$. cit., note 2, p. 470.

(17) Orderic VITAL, op. cit., note 3, II, 23. 
d'une riche héritière était un lieu commun de la littérature généalogique (18). Il convient donc d'établir des réserves sur ce fait. Du reste il n'est pas certain qu'elle ait été fille unique, la charte de restauration de Saint-Evroul atteste un Robertus filius Helgonis à Saint-Martin-sur-Giel (Heugon, canton de la Ferté-Fresnel) et au Sap-André (canton de Gacé), mais rien ne prouve que Robert ait été le fils du Helgo dont parle Orderic Vital.

En revanche, il convient de souligner que cette implantation intervient sous le règne de Richard II, époque marquée par un renouvellement de la classe dirigeante normande. Du reste en Pays d'Ouche, Giroie ne fut pas le seul à bénéficier de ce changement ; l'installation des seigneurs de Bocquencé en Normandie fut semble-t-il contemporaine (19).

Il semble que les seigneuries d'Echauffour et de Montreuil, comme celle de Bocquencé, aient été constituées à partir du patrimoine de l'ancienne abbaye d'Ouche, fondée par Saint-Evroul à la fin du VII ${ }^{\mathrm{e}}$ siècle, et détruite par les Vikings au début $\mathrm{du} \mathrm{X}^{\mathrm{e}}$ siècle. Un acte de Charles le Simple, daté de l'an 900, permet de reconstituer en partie l'étendue des biens que le monastère possédait en Hiémois et dans le Maine. Parmi les possessions, citées plusieurs localités du Pays d'Ouche apparaissent en particulier Villareridum (peut-être Villers-en-Ouche, canton de la Ferté-Fresnel) ; Balcantiam (Bocquencé, canton de La Ferté-Fresnel) et Agon (peut-être Heugon, canton de la Ferté-Fresnel) (20). Heugon faisait partie de l'honor de Montreuil. Le site de l'abbaye d'Ouche, quant à lui, dépendait semble-t-il de la seigneurie d'Echauffour. Une partie de ce patrimoine monastique fut restitué à l'Eglise lors de la restauration de l'abbaye de Saint-Evroul en 1050.

Au-delà de la question du renouvellement de l'aristocratie normande, l'implantation de Giroie fit l'objet d'enjeux spécifiques.

En effet, l'installation des Géré intervient au moment où se constitue la première seigneurie de Bellême aux confins de la Normandie et du Maine. Comme le remarque G. Louise, dès les années 1020-1025, la seigneurie de Bellême maîtrise la grande dorsale forestière qui s'étend du Mortinais au Perche. Sa domination déborde d'ailleurs déjà largement de part et d'autre de cet ensemble, notamment vers le Nord, et les nouvelles frontières de la seigneurie sont jalonnées par un ensemble de fondations monastiques qui se placent toutes sous Guillaume $\mathrm{I}^{\mathrm{er}}$ de Bellême. C'est dans ce contexte d'expansion rapide de la seigneurie de Bellême de part et d'autre de cette grande dorsale forestière qu'il faut sans doute replacer l'installation de Giroie I ${ }^{\text {er }}$ à Echauffour et à Montreuil-l'Argillé : en intercédant auprès du duc de Normandie pour permettre à son vassal d'obtenir ces deux seigneuries, Guillaume de Bellême cherchait probablement à contrôler, plus ou moins directement, les biens

(18) G. Duby, «Les jeunes dans la société aristocratique », Hommes et structures du Moyen Age, Paris, 1973, p. 222.

(19) L. MusSET, op. cit., note 4 ; D’après Orderic VITAL, II, 75-76, le lignage de Bocquencé remonte à Baudry le Teuton "qui était venu avec Viger son frère pour servir le duc de Normandie ".

(20) Recueil des Acies de Charles III le Simple, ed. Ph. Lauer, F. Lot, Paris, 1940, nº 34. 
issus du patrimoine de l'ancienne abbaye d'Ouche qui étaient vraisemblablement intégrés au comitatus du comte carolingien d'Hiémois (21). Cette tentative faite pour détacher ce secteur de l'ancien pagus d'Hiémois au profit de la seigneurie de Bellême allait être cependant contrée par les Géré eux-mêmes.

L'action entreprise par Giroie pour consolider son emprise en Pays d'Ouche est intéressante tant par les enjeux qu'elle révèle que par les moyens utilisés, en particulier en matière ecclésiastique. Sur ce point, le récit d'Orderic Vital offre plusieurs détails précieux. D'après l'auteur de l'Histoire Écclésiastique "Guillaume avait les coutumes épiscopales sur ses domaines d'Echauffour et de Montreuill'Argillé et aucun archidiacre n'osait visiter les prêtres de son honneur. En effet, Giroie, son père, après avoir obtenu le fisc d'Heugon demanda aux habitants de la contrée qui était leur évêque. Ils dirent qu'ils ne dépendaient d'aucun évêque. Celui-ci s'exclama : "c'est tout à fait injuste, plaise au ciel que je ne sois pas sans pasteur et privé du joug de la discipline ecclésiastique !" puis il s'enquit de savoir quel était le plus pieux des prélats voisins. Il mit aussitôt ses possessions sous la juridiction de Roger, évêque de Lisieux, et persuada Baudry de Bocquencé et ses gendres Vauquelin de Pont-Echanfré et Roger de Merlerault d'en faire autant. L'évêque Roger, de son côté, leur donna une exemption telle que le clergé de leurs terres ne soit pas tenu d'aller aux plaids en dehors de leurs territoires (potestatem) ni opprimés par les injustes exactions (injustis circumventionibus) des archidiacres. Guillaume Géré maintint ce privilège et le donna à Saint-Evroul avec la permission de l'évêque Hugues. Par ailleurs, Orderic Vital dit que Giroie édifia six églises : Sainte-Marie et Saint-Paul à Verneusses, Saint-Pierre à Glos, Saint-André à Echauffour, SaintGeorges à Montreuil-l'Argillé, Saint-Martin à Hauterive (22).

Ces indications posent plusieurs problèmes :

Le premier concerne les limites du diocèse de Lisieux. Montreuil et Echauffour dépendaient initialement du diocèse de Sées. Fin $\mathrm{X}^{\mathrm{e}}$ début $\mathrm{XI}^{\mathrm{e}}$, le diocèse de Sées ébauche à peine sa réorganisation, la restauration de l'évêché aurait eu lieu vers l'An Mil sous l'évêque Aszo, mais il faut attendre les années 1020-1025 pour que Guillaume de Bellême restaure le chapitre de la cathédrale de Sées. L'acte de Giroie se situe avant 1022 (date de la mort de l'évêque Roger), au moment où la famille Bellême manifeste ses appétits sur l'évêché de Sées, et il semble bien être dicté par des considérations politiques, à la fois pour contrecarrer ces ambitions et marquer le pas vis-à-vis des Bellême. S'agit-il seulement d'une velléité d'indépendance ? En fait, il est bien difficile de ne pas voir la main du duc derrière ce geste : il était dans son intérêt de faire passer cette région frontière sous la juridiction, même nominale, de l'évêque de Lisieux, beaucoup plus facile à contrôler que l'évêque de Sées. Nous ne savons

(21) G. Louise, op. cit., note 2 ; M. FAuroux, L. MuSSET, op. cit., note 16, no 33.

(22) Orderic VITAL, op. cit., note 3, II, 26-27 et II, 24. 
presque rien sur l'évêque Roger. En revanche l'un de ses successeurs Herbert est mentionné comme Normannorum ducum propinquus, l'évêché de Lisieux était donc bien tenu en main par le duc à cette époque (23).

Le second problème se situe au niveau même de la portée de la concession de l'évêque de Lisieux : «Roger donna à ces seigneurs - entendez « ils se réservèrent » - les coutumes épiscopales»(24), c'est le premier cas connu en Normandie d'accaparement des droits épiscopaux par des laïcs. Entrer dans le diocèse de Lisieux, était en quelque sorte, un moyen de légaliser le fait. Les coutumes épiscopales remontent à l'époque carolingienne; il s'agit de droits de synode, de visite et de justice. J.F. Lemarignier a remarqué qu'elles recouvraient non seulement des taxes, mais aussi, pour le droit de justice, le jugement des causes. Dans certains cas, cela englobe, non seulement les fautes relevant de l'évêque, mais également la vicaria (ce qu'on appellera plus tard la haute justice).

En définitive il semble que Giroie ait obtenu un privilège de juridiction d'archidiacre même si il est douteux que les archidiacres aient été rétablis à cette époque. Ce privilège créait du même coup des ressorts quasiment autonomes en matière de juridiction ecclésiastique. Nous ignorons comment Giroie l'utilisa pour renforcer son assise sur ses possessions, ni même s'il l'employa à ces fins, toujours est-il que la concession de Roger, en ajoutant un terme juridique à la force potentielle que représentaient les forteresses d'Echauffour et de Montreuil-l'Argillé, ne pouvait qu'accroître son autorité sur ces seigneuries.

Le troisième problème, connexe au précédent, concerne l'édification des six églises. Ces fondations, pour la plupart sur des domaines récemment acquis, permettaient non seulement à Giroie de bénéficier des revenus qui y étaient attachés, mais aussi de concrétiser et de renforcer le pouvoir que lui conférait le privilège de juridiction. C'était également un moyen d'enraciner sa lignée et de la placer sous la protection des saints les plus renommés.

Comme le constate M. Chibnall, il y a une corrélation entre la piété de Giroie et la croissance de son temporel (25). La fondation d'églises est en effet un aspect du développement de la seigneurie des Géré, la restauration de Saint-Evroul en sera le couronnement.

\section{b) L'expansion de la seigneurie}

Dans les années qui suivirent leur installation en Normandie, les Géré consolidèrent leur implantation dans le duché par des alliances matrimoniales. L'union

(23) J.F. LEMARIGNiER, Etude sur le privilège d'exemption et de juridiction écclésiastique des abbayes normandes depuis les origines jusqu'en 1140, Paris, 1937 ; G. LOUISE, op. cit., note 2 ; D. DOUGLAS, "Les évêques de Normandie 1035-1066", Annales de Normandie, t. VIII, 1958, p. 88.

(24) J.F. LEMARIGNiER, op. cit., note 23, p. 105.

(25) M. ChIBNALL, «Ecclesiastical patronage and the growth of fcudal estates at the time of the norman conquest », Annaies de Normandie, t. VIII, 1958, p. 105. 
projetée entre Giroie I ${ }^{\text {cr }}$ et la fille d'Heugon n'ayant pas abouti, il épousa Gisla, fille de Turstin de Bastembourg, dont il eut onze enfants. Ce mariage fut sans doute à l'origine des biens que la famille possédait en Lieuvin : Glos (hameau d'Heudreville en Lieuvin, canton de Thiberville) où Géré fonda une église dédiée à saint Pierre, Malouy (canton de Bernay), la terra Spinarum (Saint-Victor à Notre-Dame d'Epine (canton de Brionne) et Giverville (canton de Lieurey) (26). Les enfants de Giroie tissèrent des liens matrimoniaux avec les lignages de L'Aigle, Pont-Echanfré, du Merlerault, de Grandmesnil, ainsi qu'avec la famille ducale (Robert Géré épousa Adélaïde, cousine de Guillaume le Bâtard; Hadvis Géré veuve de Robert de Grandmesnil se maria ensuite à Guillaume, fils de l'archevêque de Rouen, Robert).

A partir des années 1030 , les Géré réussirent à consolider et à étendre leurs possessions dans plusieurs directions.

\section{Dans le Pays d'Ouche}

Vers 1032-1035, à la suite d'un conflit avec Gilbert de Brionne, les fils de Giroie obtinrent Le Sap, après une intervention de Robert le Magnifique. Visiblement les Géré bénéficient toujours de la faveur ducale sans que cela affecte pour autant leurs rapports avec les Bellême puisqu'en 1033 Guillaume Géré intervient avec d'autres vassaux de Guillaume de Bellême pour tenter de libérer leur seigneur retenu prisonnier par les Manceaux au château de Ballon (27). Le conflit avec Gilbert de Brionne rebondit quelques années plus tard, en effet vers 1041 les Géré sont impliqués dans l'assassinat de celui-ci, qui avait tenté de leur reprendre Le Sap (28).

C'est probablement dans ces années 1040 qu'il faut replacer la mainmise des Géré sur l'honneur de Bocquencé. Vers 1050, au moment de la restauration de l'abbaye de Saint-Evroul, l'abbé Thierry acheta à Ernaud d'Echauffour, fils de Giroie, sur l'ordre de Guillaume le Bâtard « la terre de Bocquencé telle que Baudry, archer du comte, l'avait tenue » (29). Les seigneurs de Bocquencé, vassaux du duc de Normandie et proches de Gilbert de Brionne (Baudry le Teuton, premier seigneur de Bocquencé, avait en effet épousé une nièce de Gilbert) furent donc apparemment victimes d'une usurpation, à laquelle le duc de Normandie tenta plus tard de remédier par le biais d'une restitution à Saint-Evroul.

\section{Dans la vallée de la Sarthe et du Sarthon}

C'est sans doute dans les années 1040 que les Géré devinrent vassaux de Geoffroy de Mayenne et s'implantèrent autour de Saint-Cénéri, aux confins du

(26) Ces biens furent ensuite concédés aux monastères de Saint-Léger de Préaux et de la Trinité du Mont Neustria Pia, ed. A. du Monstier, Rouen, 1663, p. 522 ; M. FaurouX, L. Musset, op. cit., note 16, $\mathrm{n}^{\circ} 138$.

(27) Interpolations d'Orderic Vital au manuscrit de Guillaume de Jumièges, Gesta Normannorum ducum, ed. J. Marx, Rouen, Paris, 1914, pp. 154-155.

(28) Orderic VITAL, op. cit., note 3, II, 28 ; Interpolations, op. cit., note 27, p. 156.

(29) M. Fauroux, L. Musset, op. cit., note 16. 
Maine et de l'Hiémois. Selon Orderic Vital, Guillaume Géré «détruisit spontanément son propre château de Montaigu » pour le rachat de son seigneur Geoffroy de Mayenne, que Guillaume Talvas avait capturé. Quand Geoffroy sortit des prisons de Talvas, il remercia le fils de Giroie, son fidèle vassal, en lui édifiant un château à Saint-Céneri, sur la Sarthe (30).

L'épisode se place dans le cadre des luttes que se livraient les seigneurs de Bellême et de Mayenne pour contrôler les confins du Maine et de l'Hiémois ; il allait entraîner une rupture et un premier conflit entre les Bellême et les Géré. Ceux-ci en effet réussirent à étendre leur contrôle sur la haute vallée de la Sarthe et sur la vallée du Sarthon, s'appuyant en particulier sur leurs châteaux de la Roche d'Igé et de Saint-Céneri. Cet accroissement, favorisé par Geoffroy de Mayenne, qui pouvait aussi étendre son influence en direction de l'Hiémois, était un véritable coin enfoncé dans les domaines des Bellême, barrant les routes qui menaient d'Alençon vers Domfront et Mayenne. Guillaume Talvas ne s'y trompa pas. A l'occasion de son mariage, il attira Guillaume Géré dans un guet-apens, le mutila, et le jeta en prison dans une tour du château d'Alençon. En riposte, ses frères dévastèrent les territoires de Talvas (31). L'enjeu du conflit dépasse la simple rivalité pour le contrôle de la haute vallée de la Sarthe et du Sarthon. Les Géré représentaient un réel obstacle aux ambitions des Bellême. Ils étaient non seulement vassaux d'un puissant concurrent, Geoffroy de Mayenne, qui, grâce à eux mordait sur l'Hiémois, mais également des fidèles des ducs de Normandie qui, par leur action, avaient pu détacher Echauffour et Montreuil de ce même pagus. Le conflit semble avoir tourné à l'avantage des Géré, puisque dans les années 1050 ceux-ci conservaient l'essentiel de leurs possessions et leurs châteaux. Au moment de la restauration de Saint-Evroul, vers 1050, la seigneurie des Géré paraît donc être à son apogée.

\section{c) La fondation de Saint-Evroul}

Nous ne nous arrêterons pas sur les détails de la restauration de l'abbaye d'Ouche par les Géré et les Grandmesnil, minutieusement relatée par Orderic Vital (32). L'événement a une double portée.

Sur le plan ecclésiastique, cette restauration s'inscrit dans le mouvement de restitution des biens et des droits ecclésiastiques, entamé depuis le début du $\mathrm{XI}^{\mathrm{e}}$ siècle. Le concile de Reims en 1049 avait interdit aux laïcs l'usurpation des coutumes ecclésiastiques. Nous avons vu qu'une partie importante des terres concédées aux

(30) Orderic VITAL, op. cit., note 3, II, 27-28.

(31) Ibidem II, 15 ; Interpolations, op. cit., note 27, pp. 163-164.

(32) Ibidem II, 15-22, 31-42; Interpolations, pp. 174-177. 
Géré provenait d'anciens patrimoines monastiques, c'était le cas autour de Montreuil-l'Argillé et d'Echauffour, mais aussi très probablement pour Saint-Céneri (où un monastère avait été fondé par l'ermite Cénéri au vi ${ }^{\mathrm{e}} \mathrm{s}$.). Par ailleurs, les Géré disposaient de droits ecclésiastiques importants, en particulier de privilège d'exemption accordé à Giroie par l'évêque de Lisieux. En 1050, les Géré et leurs vassaux cédèrent à l'abbaye de Saint-Evroul non seulement une partie de ces droits (dont le privilège d'exemption) mais aussi des terres qui appartenaient à l'ancienne abbaye d'Ouche, notamment à Bocquencé, à Heugon, à Saint-Evroul Notre-Dame du Bois...

Sur le plan politique, la fondation d'un monastère au cœur des domaines du lignage consacrait l'enracinement des Géré en terre normande.

\section{L'éviction des Géré (vers 1059-1088)}

\section{a) La fin de la première seigneurie}

Les années qui suivirent le Val ès Dunes furent marquées par un retour en force du pouvoir ducal et des luttes violentes entre Guillaume le Bâtard ct scs principaux voisins : le comte d'Anjou et le roi de France.

Vers 1049, le comte d'Anjou occupa Domfront et Alençon; le duc de Normandie les reprit vers 1052 et fit édifier le château d'Ambrières, dans la seigneurie de Mayenne. Ces succès inquiétèrent le roi de France qui s'allia avec le comte d'Anjou en 1053. Dans le même temps, le seigneur de Moulins-la-Marche remit son château à Henri I ${ }^{\mathrm{cr}}$. Une première campagne eut lieu en 1054 et se solda par un échec français. En 1057, le roi de France tenta une autre invasion qui aboutit au même résultat.

Ces événements n'allèrent pas sans poser de problèmes pour les lignages établis aux confins de la Normandie et du Maine. C'est à ce moment, entre 1049 et 1055, que G. Louise place la destruction de la première seigneurie de Bellême, aggravée par les dissensions au sein du lignage partagé entre ses fidélités royales, normandes et angevines (33). La seigneurie perd alors sa partie occidentale au profit de la Normandie (Domfront, Alençon) et passe progressivement dans la mouvance normande (Mabille héritière de Guillaume Talvas épousant Roger II de Montgommery), ce qui permettait de jeter les bases d'une future conquête du Maine.

Orderic Vital se montre très discret sur l'attitude des Géré pendant cette période. Balancés entre leurs allégeances normandes et mancelles, leur choix n'était pas facile. Guillaume Géré et ses fils, vassaux du duc de Normandie pour Echauffour et Montreuil-l'Argillé, regardaient plutôt du côté normand; mais Robert Géré était

(33) G. LouISE, op. cit., note 2, pp. 498-529. 
vassal de Geoffroy de Mayenne pour Saint-Céneri. Il semble cependant que le lignage soit resté fidèle à Guillaume le Bâtard (qui confirme la fondation de Saint-Evroul en 1050), y compris Robert Géré qui souscrit dans plusieurs actes du duc de Normandie ; c'est peut-être à ce moment, vers 1050-1055, qu'il faut replacer le mariage de Robert avec une cousine de Guillaume le Bâtard. Cette fidélité n'allait pas se prolonger. En effet, vers 1059-1060 Robert Géré se rebella contre le duc de Normandie. Orderic Vital ne donne guère de précisions sur les motifs de cette rebellion, indiquant simplement « qu'avec l'aide des Angevins il fortifia ses châteaux de Saint-Céneri et de la Roche d'Igé. Il tint un moment contre le duc qui l'assiégea avec des forces normandes " (34). Robert mourut empoisonné par sa femme en février 1060, son neveu Ernaud d'Echauffour continua la lutte, puis se soumit au duc. Il prêta hommage à Guillaume le Bâtard qui lui restitua Montreuil, Echauffour, Saint-Céneri et tout son héritage paternel. Dès 1061 cependant, le duc exila Ernaud d'Echauffour, ainsi que d'autres seigneurs normands. Ses domaines furent concédés à Roger de Montgommery tandis qu'Echauffour recevait une garnison ducale. Parallèlement, Guillaume le Bâtard imposa un nouvel abbé à Saint-Evroul après avoir exilé l'abbé Robert de Grandmesnil.

Cette éviction des Géré est à replacer dans la lutte que se livrent Normands et Angevins pour contrôler les confins normanno-manceaux. La destruction de la première seigneurie de Bellême n'avait pas eu seulement pour effet de faire passer une grande partie de celle-ci dans la mouvance normande ; elle avait également permis au comte d'Anjou de renforcer son influence dans le Nord du Maine (35). Cela favorisa sans doute le glissement des Géré dans l'orbite angevine. Le duc de Normandie réagit d'abord en ramenant les Géré dans sa vassalité. Orderic Vital considère que l'exil qui suivit fut une machination orchestrée par Mabille de Bellême et Roger de Montgommery. Il n'est pas difficile d'y voir aussi une réorganisation de la frontière sud du duché : la confiscation des biens des Géré au profit de Roger II de Montgommery permettait de renforcer considérablement la «base arrière à la conquête du Maine » (G. Louise) que représentait la seigneurie de ce dernier. Elle s'inscrit, semble-t-il, dans la continuité de la politique ducale qui allait mener à la conquête du Maine en 1063.

Ainsi, la seigneurie des Géré avait pu s'étendre en jouant sur l'instabilité des confins entre la Normandie et le Maine, sur les intérêts contradictoires des seigneurs de Bellême et de Mayenne, du duc de Normandie et du comte d'Anjou, en particulier pendant la minorité de Guillaume le Bâtard. Avec le retour en force du pouvoir ducal, les Géré se trouvèrent pris dans un processus de réorganisation des frontières du duché qui ne s'accommodait pas des ambiguïtés grâce auxquelles leur seigneurie avait prospéré.

(34) Orderic VITAL, op. cit., note 3, II, 72-73.

(35) G. Louist, op. cit., note 2, pp. 530-38. 


\section{b) Les Géré en Italie}

L'exil d'Ernaud d'Echauffour marqua un coup d'arrêt décisif à l'ascension des Géré. Ernaud mourut empoisonné en 1064 après avoir cherché refuge auprès de son parent Giroie de Courville et tenté de recouvrer ses possessions. Le lignage, dispersé, ne reprit pied à Saint-Cénéri qu'en 1088 et dut attendre 1119 pour retrouver ses fiefs d'Echauffour et de Montreuil-l'Argillé. Chassés de Normandie, certains de ses membres firent carrière en Italie. Nous n'insisterons pas sur cet épisode (36), mais celui-ci appelle cependant deux remarques :

- l'implantation du lignage en Italie remonte en fait à une période antérieure à l'exil des Géré : l'un des fils de Giroie I ${ }^{\text {er }}$ l'Ancien, Raoul " Maucouronné » (ainsi surnommé car bien qu'étant clerc il gardait le goût des exercices chevaleresques) avait été étudier la médecine à Salerne ; surtout Guillaume de Montreuil, fils de Guillaume Géré s'y était établi avant 1056 (date à laquelle son père vint l'y rejoindre), avait épousé la fille de Richard, prince de Capoue et avait reçu de celui-ci une partie du comté d'Aquin ;

- c'est auprès de Guillaume de Montreuil que vint se réfugier le fils d'Ernaud, Guillaume d'Echauffour. Il s'y installa définitivement et fit fortune. L'un de ses descendants cst plusicurs fois citć dans le catalogus baronum du royaume normand de Sicile au milieu du XII ${ }^{\mathrm{c}}$ siècle (37).

\section{La seconde seigneurie des Géré (1088-1294)}

\section{a) La récupération des fiefs de Saint-Céneri, d'Echauffour et de Montreuil (1088-1119)}

La restitution du château de Saint-Céneri à Robert II Géré prend place dans le cadre de la lutte entre Robert Courteheuse et Robert de Bellême. Après la mort de Guillaume le Conquérant, le fils de Roger de Montgommery avait chassé de ses châteaux les garnisons que le duc y avait laissées. En 1088, contrôlant mal la situation en Normandie, Robert Courteheuse tenta de rallier à lui l'aristocratie mancelle. Après avoir repris Ballon aux rebelles, les Normands et les Manceaux fidèles au duc vinrent assiéger le château de Saint-Céneri, où Robert de Bellême avait installé une garnison commandée par Robert Quarrel. Faute de vivres, la place capitula. A la demande de Geoffroy de Mayenne et des chefs manceaux, le duc de Normandie restitua Saint-Céneri à Robert II Géré, en échange de son service et de sa fidélité. Dans les années qui suivirent, la situation évolua rapidement. Robert de Bellême se

(36) Outre Orderic VITAL, op. cit., note 2, II, 56-58-69-70, 88-94-109, la principale source relatant les exploits des Géré en Italie est l'Histoire des Normands de Aimé de Mont-Cassin, ed. V. de Bartholomeis, Rome, 1935.

(37) Catalogus baronum, ed. E.M. Jasmison, Fonti per la Storia d'Italia, vol. 101, 1972, n 362-363, pp. $62-63$. 
réconcilia avec le duc de Normandie, l'aristocratie mancelle se rebella contre Robert Courteheuse, et choisit son propre comte. Dans les conflits qui opposèrent les fils de Guillaume le Conquérant, Robert II Géré opta pour Henri Beauclerc, qui reprit le château de Domfront à Robert de Bellême, vers 1092. Dans le même temps, Robert II Géré pilla les campagnes de l'Alençonnais. Décidé d'en finir avec cette menace, Robert de Bellême, après une première attaque infructueuse, prit d'assaut le château de Saint-Céneri, laissé quasiment sans défense. L'année suivante, vers 1094, Robert II Géré fit reconstruire le château de Montaigu et continua les hostilités contre Robert de Bellême. Celui-ci persuada le duc de venir assiéger Montaigu. Geoffroy de Mayenne et les grands du Maine vinrent alors trouver Robert Courteheuse pour plaider la cause de Robert Géré. Le duc cherchant sans doute à s'octroyer les bonnes grâces des Manceaux accepta que Saint-Céneri soit restitué à Robert Géré, à condition que le château de Montaigu soit détruit (38).

Ainsi, autour de Saint-Céneri, la situation est redevenue pratiquement la même qu'un demi-siècle auparavant. Le duc de Normandie n'a certes pas perdu le contrôle de la région, puisque par deux fois il obtint la restitution de Saint-Céneri à Robert II Géré, mais l'influence mancelle et angevine est toujours aussi présente: Robert Courteheuse agit sur la demande de Geoffroy de Mayenne et des principaux chefs manceaux, espérant sans doute rallier à lui un certain nombre d'entre eux. D'autre part, lors de l'attaque de Robert de Bellême sur Saint-Céneri, la garnison du château était commandée, en l'absence de Robert II Géré, par deux manceaux : Payen de Montdoubleau et Rotrou de Montfort-le-Rotrou. Robert II Géré paraît alors entretenir des rapports étroits avec plusieurs seigneurs du Maine (entre 1094 et 1100 , il épouse la fille d'un seigneur manceau, Avesgaud de Connerré) et avec l'abbaye de Saint-Vincent du Mans (39).

La restitution d'Echauffour et de Montreuil prend place après la chute de la seconde maison de Bellême (1112-1113). Vers 1118, pour des raisons qu'Orderic Vital ne précise pas, Robert II Géré défendit le château de Saint-Céneri contre Henri ${ }^{\mathrm{cr}}$ et demanda l'aide du comte d'Anjou qui mit le siège devant le château de la Motte Gauthier. Ce conflit s'inscrit dans le cadre de la lutte entre les Bellême et le roi. Henri $\mathrm{I}^{\text {er }}$ après sa victoire sur Robert Courteheuse, décida de restaurer les prérogatives royales exercées par son père. La paix fut de courte durée, Robert de Bellême se révolta contre le roi d'Angleterre, et gagna à sa cause le comte d'Anjou et le roi de France. Emprisonné en 1112 par Henri I ${ }^{\text {er }}$, ses fils Robert et Guillaume Talvas (comte de Ponthieu) continuèrent la lutte. En 1118, Henri Beauclerc fut battu à Alençon. En 1119, il restitua à Guillaume Talvas les terres normandes de son père en

(38) Orderic Vital, op. cit., note 3, III, 261-62, 292-93, 297-98, 418-21; O. Gulllot, Le comte d'Anjou et son entourage au Xr' siècle, Paris, 1972 ; L. Halpuen, Le comte d'Anjou au Xr' siècle, Paris, 1906.

(39) Orderic VITAL, op. cit., note 3, III, 419. Cartulaire de Saint-Vincent du Mans, ed. R. Charles et Vte Menjot d'Elbenne, Le Mans-Mamers, 1886-1913, n' 139, 140, 511. Les Géré possédaient encore des biens dans la région de Connerré et du Mans au XIII ${ }^{\mathrm{e}}$ siècle. Voir Liber controversarium Sancti Vicenti Cenomannensis ou second cartulaire de Saint-Vincent du Mans, ed. A. Chedeville, Paris, 1968, $\mathrm{n}^{\circ} 81$, pp. 141-142. 
Normandie et à Robert II Géré les fiefs d'Echauffour et de Montreuil-l'Argillé (40). Apparemment Robert II Géré a pris le parti de Robert de Bellême, et en fut récompensé après la défaite du roi, par la restitution d'Echauffour et de Montreuill'Argillé, confisqués en même temps que les autres terres de Robert de Bellême. Il est également possible que les raisons de l'intervention d'Henri $\mathrm{I}^{\text {er }}$ à Saint-Céneri relèvent simplement du souci de mieux contrôler la frontière mancelle au moment où celui-ci était en conflit avec le comte d'Anjou. Par la suite, le roi aurait préféré reconcéder les deux châteaux aux descendants de leurs anciens titulaires, plutôt que de les redonner au fils de Robert de Bellême.

Cinquante-sept ans après leur expulsion de Normandie, les Géré revenaient autour de l'abbaye d'Ouche ; mais la situation était bien différente de celle des années 1050. Désormais, les seigneurs de Saint-Cénéri ne joueront plus aucun rôle politique.

\section{b) Un rôle politique effacé (1119-1294)}

Alors que les Géré avaient été mêlés de très près aux confrontations qui avaient agité les confins de la Normandie et du Maine au XI ${ }^{\mathrm{c}}$ et au début du XII ${ }^{\mathrm{c}}$ siècle, ils ne semblent plus prendre une part active aux événements après 1120. C'est le cas lors de la phase de troubles qui s'ouvre après la mort d'Henri ${ }^{\text {er }}$ (1135), pendant laquelle Robert III Géré ne joua apparemment aucun rôle déterminant, bien que le Pays d'Ouche ait été touché par les exactions des seigneurs de la région (Montreuill'Argillé fut brûlé en 1138) (41). L'appréciation de la place des Géré au milieu du $\mathrm{XII}^{\mathrm{c}}$ siècle est cependant contrariée par le hiatus qui existe dans nos sources entre le début des années 1140 (Orderic Vital s'arrête en 1142) et les années 1170.

Pour la période qui s'étend de la fin du XII siècle à 1294, la principale préoccupation qui transparait est de savoir comment les barons de Saint-Céneri (c'est ainsi que nous appellerons désormais les Géré qui ont troqué leur nom pour celui de Saint-Céneri vers $1170-1180$ ) ont vécu l'intégration de la Normandie au royaume de France.

La conquête de la Normandie débuta en 1202, après la confiscation des fiefs de Jean Sans Terre prononcée par la cour du roi de France. Dans les mois qui suivirent plusieurs barons du royaume anglo-normand se rallièrent à Philippe Auguste, en particulier Robert comte d'Alençon. Cette situation rendait délicate la position des sires de Saint-Céneri vassaux du comte d'Alençon. Visiblement Guillaume II de Saint-Céneri resta fidèle au roi d'Angleterre, mais ce ne fut pas le cas du principal de

(40) Orderic VITAL, op. cit., note 3, IV, 323, 331-34, 347-48.

(41) Ibidem, V, 106. 
ses vassaux, Payen de Montreuil (42). C'est peut-être ce choix qui explique les exactions qu'ils eurent à subir par la suite. En effet il semble bien que pendant une partie du XIII ${ }^{c}$ siècle les sires de Saint-Cénéri aient perdu leur domaine de Montreuill'Argillé. Vers 1230, un certain Gervais de Gaillon confirme à Saint-Evroul les donations faites par les Géré à la fin du $\mathrm{XII}^{\mathrm{c}}$ siècle et concède des biens à Montreuil-l'Argillé. Une quarantaine d'années plus tard, en 1269, l'un de ses descendants Jean de Gaillon porte le titre de «seigneur de Montreuil» (43). Il est possible de rattacher cette usurpation aux méfaits de Lambert Cadoc, châtelain de Gaillon, connu pour ses exactions en Normandie, et dont Gervais de Gaillon semble être un proche parent. Après 1269, le lignage de Gaillon n'est plus attesté à Montreuil-l'Argillé, qui fut probablement restitué aux sires de Saint-Cénéri dans les années qui suivirent la constitution de l'apanage d'Alençon (44).

Hormis ces difficultés, peu d'éléments transparaissent sur les sires de SaintCénéri au XIII ${ }^{\mathrm{c}}$ siècle. Ceux-ci semblent assez représentatifs du milieu aristocratique auquel ils appartiennent. Servant le roi au rang de chevalier banneret, Guillaume III de Saint-Cénéri fut semond à l'ost du roi de France pour aller contre le comte de la Marche en 1242 (45). Ils connurent les mêmes problèmes que bon nombre de lignages aristocratiques, notamment dans le domaine financier où ils s'endettèrent auprès de Saint-Evroul. Cette mauvaise situation financière explique sans doute pourquoi le dernier sire de Saint-Cénéri, Jean, est toujours écuyer à l'âge de 35 ans en 1293 un an avant sa mort (46). L'héritage, tombé en quenouille, devint alors une proie facile aux lignages ambitieux et passa dans les familles de Tybouville et d'Harcourt de Beaumesnil.

Les derniers barons de Saint-Cénéri paraissent donc différents de leurs turbulents ancêtres. Après avoir récupéré leurs possessions en 1118-1119, les Géré abandonnèrent tout rôle politique. L'arrivée des Plantagenêts en Normandie puis sur le trône d'Angleterre, au milieu du XII ${ }^{\mathrm{e}}$ siècle, reléguait au second plan l'importance stratégique de leur position frontalière. Fidèles au roi d'Angleterre, puis au roi de France, nous les voyons désormais agir essentiellement dans le cadre de leur seigneurie.

Ce sont les structures de celle-ci qu'il convient maintenant de mettre en place, $\mathrm{cn}$ insistant principalement sur les outils qui permirent aux Géré d'asseoir leur implantation sur les confins normanno-manceaux : les châteaux et les bourgs.

(42) Le 7 mai 1203 le roi d'Angleterre mande à son bailli Jean de Préau "quod faciatis habere Willelmo de Sancto Celerino terram quam Paganus de Mosterolo qui est contra nos, tenuit de feudo ipsius Willelmiin baillia tua " Magni Rotuli..., ed. Lechaudé d’Anisy, MSAN XV, Paris 1845, p. 121, col. 1.

(43) Cartulaire de Saint-Evroul, chartes n 50, 51, 691-692-693-694.

(44) L'apanage d'Alençon fut constitué en 1268 par Saint-Louis en faveur de son fils Pierre à partir des terres de l'ancien comté d'Alençon réunies au domaine royal en 1221. En 1277 le roi de France reconnut que la baronnie de Saint-Cénéri relevait de l'Apanage d'Alençon; A. VALLEZ, La construction du comté d'Alençon 1269-1380, Annales de Normandie, mars 1972.

(45) R.H.G.F., XXXIII, p. 684, p. 728 ; XXXIV, p. 244 c.

(46) Archives de l'Orne $\mathrm{H} 881$. 


\section{LA MATTTRISE DU SOL : LES CHÂTEAUX ET LES BOURGS}

C'est en prenant appui sur des châteaux que les Géré purent étendre et consolider leur seigneurie. Le château est, avec le bourg, un élćment cssentiel de la maîtrise du sol et des hommes.

\section{Les châteaux}

Les barons de Saint-Céneri comptent parmi les plus anciennes familles châtelaines de Normandie puisqu'avant 1050 ils tenaient simultanément au moins trois châteaux.

\section{a) Montreuil-l'Argillé}

Les sources concernant le château de Montreuil-l'Argillé sont rares. D'après Orderic Vital, l'oppidum de Montreuil fut concédé à Giroie avec celui d'Echauffour, au début du XI ${ }^{\mathrm{c}}$ siècle, vers 1032-1033. Gilbert de Brionne tenta de prendre Montreuil aux frères Géré, mais la forteresse ne semble pas avoir joué un grand rôle dans l'échauffourée : si l'on s'en tient au récit, le combat eut lieu in aperto campo, en rase campagne. Montreuil-l'Argillé fut brûlé avec Pont-Echanfray en 1138, mais nous ne savons pas si le château a été touché.

Par la suite, nous n'avons plus d'information sur le château. La localité est plusieurs fois citée pendant la guerre de Cent Ans. En 1419, un certain Hugues Luterell est agréé à recevoir la soumission de la villa de Montreuil. En avril 1419, Henri V d'Angleterre concède à John Newton le manerium de Montreuil; un document du 2 juillet 1428 signale la présence d'une garnison anglaise à Montreuil. Cependant aucun de ces trois textes ne réfère précisément à la fortification (sauf peut-être le mot manerium, mais le terme a aussi plusieurs autres sens). Il faut attendre les aveux de 1681 pour avoir une brève description de l'ensemble : « un vieux manoir et motte de chasteau à double fossés estant en ruine » (47).

Le château de Montreuil-l'Argillé se trouve à mi-pente sur une colline qui domine la Guiel. D'après le cadastre, le site s'appelle «le bourg ».

(47) Orderic VITAL, Histoire Ecclésiastique, II, 23, 24-25, V, 106. Rôles normands et français tirés des archives de la tour de Londres par Brequigny, ed. A. Charma, MSAN XXIII, Paris 1856, $\mathrm{n}^{\text {os }} 1216,477$. Actes de la Chancellerie d'Henri VI concernant la Normandie sous la domination anglaise 1422-1435, ed. P. Le Cacheux, Paris, Rouen, 1908, t. II, pp. 100-103. Aveu de 1681, Archives Nationales, p. 867. 
La voie antique de Lisieux à Chartres par Orbec, Pont-Echanfray, Rugles, franchit la Guiel à Montreuil-l'Argillé et longe la forteresse. Une autre route antique de Rouen au Mans par Broglie, Bernay, Brionne passe à l'Ouest de la commune (48).

La fortification est une enceinte, de forme grossièrement quadrangulaire, qui s'étend sur environ $70 \mathrm{~m}$ de long. Elle est formée d'un rempart en terre de 5 à $6 \mathrm{~m}$ de hauteur, précédé d'un large fossé. A l'Ouest, l'enceintc s'arrête brutalement par un talus contigu aux habitations du bourg. On distingue plusieurs structures à l'intérieur de l'enceinte dont au Nord-Est, une motte haute d'une dizaine de mètres sur laquelle on distingue les traces d'un bâtiment en pierre, probablement le donjon, au Nord, les ruines d'une ancienne construction adossée au rempart et, au Sud, d'autres vestiges d'anciennes constructions.

De part et d'autre de l'enceinte, le cadastre napoléonien indique la présence de deux parcelles boisées partant l'une du Nord, l'autre du Sud de l'enceinte et rejoignant semble-t-il la Guiel. Il s'agit peut-être de la trace de remparts et de fossés comblés depuis, délimitant une enceinte beaucoup plus vaste qui enfermait peut-être une partie du bourg (49).

Au total, le château de Montreuil-l'Argillé présente deux enceintes emboîtées, le dispositif étant renforcé au Nord-Est par une motte accolée au rempart.

\section{b) Echauffour}

Comme Montreuil-l'Argillé, la forteresse d'Echauffour est qualifiée d'oppidum par Orderic Vital. Le moine d'Ouche utilise également le terme de castellum. Nous avons vu que, vers 1062-1063, Ernaud fils de Guillaume Géré attaqua le castrum d'Echauffour et l'incendia. Echauffour fut de nouveau brûlé vers 1088 par Geoffroy comte du Perche, mais le récit ne précise pas si le château fut touché. En 1138, Robert III Géré ouvrit son castrum d'Echauffour à Simon Le Roux qui s'en servit de base pour mettre à sac les terres du comte de Leicester. Le premier document diplomatique mentionnant la fortification date de la fin $\mathrm{du} \mathrm{XI}^{\mathrm{c}}$ siècle : d'après une charte transcrite par Orderic Vital, Roger de Montgommery donna la dîme de tous les revenus de ce castrum. En 1135, Robert III de Saint-Cénéri reconnut la possession du fief de Raoul l'Orphelin à l'abbaye Saint-Martin de Sées, mais retint un certain nombre d'hommes pour clorc son castellum d'Echauffour. Ensuite, nous n'avons plus de renseignements jusqu'à la guerre de Cent Ans.

La Chronique des quatre premiers Valois signale que Philippe de Navarre prit le château d'Echauffour en 1358. En 1362 «les garnisons de anglois qui estoient en Normandie firent une chevaucie, ceulx de Honfleu, Auvilliers, Echaufou, et de Tuebeuf, d'environ quarante-cinq glaives et vingt-huit archiers et cinquante taleva-

(48) R. Doranlo, Les voies de la civitas des Lexovii, BSNEP 1937, pp. 145-200... Ph. LANIER, Les voies de communications anciennes de la cité des Lexovii ; mémoire de maîtrise, Caen, 1981-1982, pp. 55-78.

(49) Voir notamment: L. Deglatigny, Notes sur quelques enceintes de l'arrondissement de Bernay, Rouen, 1926-1931. 
chiers ". La Chronique normande $d u X I V^{e}$ siècle cite la forteresse parmi les châteaux fortifiés par les Anglais en 1363. L'année suivante il est assiégé pendant 42 jours. Du Guesclin participa aux opérations.

Le château d'Echauffour fut en grande partie démoli au début du XvII ${ }^{\mathrm{e}}$ siècle. Gaspard Erard, seigneur du lieu, prit part aux guerres de Religion et aux troubles qui agitèrent le Pays d'Ouche après la mort d'Henri IV. Le 28 janvier 1614, le Parlement de Rouen décide d'écrire à la Reine-mère, la priant d'autoriser à faire donner le canon «pour faciliter la prise de la maison forte du baron d'Echauffour en laquelle il estoit assiégé par les prévots et vice bailli ». Apparemment la fortification avait déjà été transformée en maison forte avant 1614, mais était encore capable de subir un siège à cette date. Le démantèlement définitif de la forteresse eut sans doute lieu sous Richelieu. Une clé de voûte d'un des bâtiments de la ferme du château, probablement construit avec des matériaux de récupération, porte la date de 1632. L'aveu de 1681 offre une brève description de l'ensemble « manoir et chasteau seigneurial environné de doubles fossez, tours, collombiers, pressoirs, douves, pont-levis, édifice, jardins, grand parc fermé de murailles... » (50).

Le site (appelé « le château » dans le cadastre) est situé à 305 m d'altitude, sur une colline qui domine le bourg. Il est possible que le chemin de Planches à Echauffour reprenne le tracé d'une ancienne voie antique: d'importants vestiges gallo-romains ont été découverts à Planches (51); d'autre part, sur le bord de cette route, à environ $750 \mathrm{~m}$ au Sud du bourg d'Echauffour, on relève un lieu-dit « Les Pierres Levées ». Une autre voie ancienne existait entre L'Aigle et Sées, par Echauffour, elle est attestée par des textes médiévaux et demeure la route principale jusqu'aux XVIII ${ }^{\mathrm{e}}$-XIX ${ }^{\mathrm{e}}$ siècles. Située en bordure du plateau de la forêt de SaintEvroul, cette voie passe à proximité d'un lieu-dit «Les Terres Noires » (à Beaufay); plusieurs tombeaux ont été exhumés le long de la route d'Echauffour à Sées, sur la commune d'Echauffour (52).

Il reste peu de chose de l'ancienne forteresse des Géré. Le bâtiment principal, très remanié aux $\mathrm{XVII}^{\mathrm{e}}$ et $\mathrm{XVIII}^{\mathrm{e}}$ siècles occupe une partie du château démantelé. La façade nord a conservé une tour écrêtée. A l'intérieur de la demeure, un épais mur de refend est cncore visible. Les fondations des parties abattues se dessinent à certains endroits dans les allées du jardin, notamment au Sud et à l'Est de la maison.

(50) Orderic VITAL, Histoire Ecclésiastique, II, 127, 83; III, 301-302: V, 106 ; II, 413. Archives de l'Orne H 938, Cartulaire de Saint-Martin de Sées, $f^{\circ}$ 114. Chronique des quatre premiers Valois 1327-1393, ed. S. Luce, Paris, 1862, pp. 88, 107, 154. Chronique normande du XIV" siècle 1294-1376, ed. V. de Bartholomeis, Rome, 1935, p. 174. Cahier des Etats de Normandie sous les règnes de Louis XIII et Louis XIV, ed. Ch. de Robillard de Beaurepaire, Rouen, 1876, t. 1, p. 287 . Archives Nationales, p. 867.

(51) Voir notamment G. HUBERT, Répertoire bibliographique des travaux, communications, et notes concernant l'archéologie antique du département de l'Orne, des origines au $\mathrm{x}^{\mathrm{c}}$ siècle, B.S.A.N., t. 54, 1957-1958, pp. 1 à 75.

(52) X. Rousseau, Dictionnaire du pays d'Argentan: Echauffour, Pays d'Argentan, n 78 , déc. 1948, p. 73. 
Le château d'Echauffour avait sans doute un aspect voisin de celui de Montreuil-l'Argillé. Le fossé, bien que comblé dans toute la partie nord de la forteresse, est quasiment intact au Sud-Est. On peut penser qu'il délimitait une enceinte large d'une soixantaine de mètres, le tertre semble être légèrement surélevé par rapport au sol environnant. Les remaniements successifs de l'ouvrage ne permettent pas de dire s'il y a eu un rempart de terre ou une mottc.

\section{c) La motte des Sapins}

A environ $2,5 \mathrm{~km}$ au Sud-Est du château d'Echauffour, se dresse la motte dite des Sapins (du nom de la propriété dont le site dépend). La fortification n'est mentionnée dans aucun document et nulle famille aristocratique ne s'y rattache. Le tertre de forme circulaire est entouré d'un fossé large de $3,50 \mathrm{~m}$ à $5 \mathrm{~m}$, dont toute la partie orientale est remplie d'eau. E. Vimont signalait en 1886 un puits recouvert d'une large pierre plate, situé au Sud, près de l'entrée de la fortification. Le site a été endommagé par des fouilles sauvages au siècle dernier. "Au Sud-Ouest, M. Albéric Desclos, propriétaire du terrain, aplanit le sol et comble une partie du fossé qui reste à sec... cet homme se propose de vider et de fouiller son puits où existent, dit-on, des trésors assez considérables » (53). De fait, à l'emplacement du puits on découvre aujourd'hui un grand trou; les fossés ont été en partie remblayés, et la motte couverte de bois, et haute de $3,50 \mathrm{~m}$ en 1886 , sert maintenant d'herbage.

Dans quel but édifia-t-on cette motte ? Sa situation, sur une colline dont le pied est baigné par la Risle, permettait d'observer la vallée de la Risle depuis Planches jusqu'à Sainte-Gauburge. Cet emplacement ainsi que l'absence de basse-cour incite à penser qu'il s'agit d'une motte de guet.

\section{d) Montaigu}

Le castrum de Montaigu, cité pour la première fois dans les années 1040, fut détruit quelques temps après. Reconstruit vers 1094-1095, il est à nouvcau démoli dans les mois qui suivirent (54). Son histoire reste donc très liée à celle du château de Saint-Cénéri et aux luttes entre Bellême et Géré, aucun document ne l'atteste par la suite.

Le château de Montaigu occupe un point stratégique, au confluent de la Sarthe (au Nord-Est) et de l'Ornette (à l'Ouest). Il s'agit d'un éperon barré par un rempart semi-circulaire en terre et en pierre. Un fossé long d'environ $150 \mathrm{~m}$ se trouve devant

(53) Voir également E. VIMONT, «Echauffour et ses monuments ». Bulletin de la Société scientifique Flammarion d'Argentan, $\mathrm{n}^{\circ} 4$, 1886, pp. 253-68.

(54) Orderic VITAL, Histoire Écclésiastique, II, 27-28, III, 420-21. 
le rempart. Au bord de l'éperon, sur une parcelle nommée " château », apparaissent des vestiges en pierre sèche; il s'agit peut-être d'un bâtiment effondré.

\section{e) Saint-Céneri-le-Gérei}

Le castrum de Saint-Céneri fut construit peu après la destruction de Montaigu, vers 1040-1045. Il subit par la suite maintes transformations. Vers 1059-1060 Robert ${ }^{\text {er }}$ Géré le fortifia avec l'aide des Angevins, avant d'y être assiégé par le duc de Normandie. De nouveau investi en 1088, il fut rendu à Robert II Géré qui le fortifia avec des murs, des remparts et des tours de guet : "Robertus dux... Roberto Geroio castellum Sancti Serenici reddidit. Ille vero fere XXVI annis postmodum tenuit, murris et vallis zetisque munivit...". En 1093, Robert de Bellême prit le castrum quasiment sans combat. Il fut restitué à Robert II Géré l'année d'après. En 1118, le château fut une nouvelle fois assiégé par le roi Henri $\mathrm{I}^{\mathrm{er}}$. Après trois quarts de siècle d'une existence mouvementée, il faut attendre la guerre de Cent Ans pour voir Saint-Céneri jouer à nouveau un rôle de premier plan dans les événements militaires. La château fut assiégé à trois reprises par les Anglais, après deux échecs (en 1430 et 1432), la forteresse tomba entre leurs mains fin janvier 1434 (n.s.). Elle fut presque aussitôt détruite, en février 1434 (n.s.), Jean Stanelawe, gouverneur général des finances fut envoyé auprès du comte d'Arundel pour faire procéder à sa démolition (55).

Le site du château de Saint-Céneri occupe une boucle resserrée d'un méandre de la Sarthe, commandant ainsi le passage de la rivière. Louis Duval signalait en 1892 l'existence de fossés au Nord de la place. Malheureusement ils ne sont plus visibles à l'heure actuelle, l'emplacement étant occupé aujourd'hui par la mairie et l'école. Le château avait la forme d'un parallélogramme irrégulier. Au Nord, une plate-forme domine l'ensemble, elle est surmontée d'une motte. Au centre sur une seconde motte, se dressait le donjon. Ces vestiges étaient encore visibles au $\mathrm{XIX}^{\mathrm{e}}$ siècle ; mais une maison a été construite sur le tertre au début du $\mathrm{XX}^{\mathfrak{c}}$ siècle. D'après $\mathrm{R}$. Jouanne des caves voûtées subsistent et lui servent d'assise. Le donjon en pierre était de forme carrée (56).

Une enceinte de pierre entourait l'ensemble du site; on en voit encore d'importants vestiges sur le bord de la route d'Alençon. Louis Duval parlait

(55) Orderic VITAL, Histoire Ecclésiastique, II, 27-28, 72-73, III, 297-98, 418-420, V, 323. Les sources concernant le siège de Saint-Cénéri pendant la Guerre de Cent Ans sont nombreuses ; plusieurs chroniques contemporaines signalent l'événement (ex. celle d'Enguerand de Monstrollet, ed. L. Douet d'Arcq, Paris, 1861, t. V, pp. 100-101; Le Jouvencel de Jean de Breuil, ed. L. Lecestre, Paris, 1887, t. I, pp. 141 à 599. Ainsi que plusieurs documents aux Archives Nationales (ex. A.N.K. 63, $\mathrm{n}^{\circ}$ 29) et aux Archives de l'Orne (A. 406). Voir aussi H. Pastoureau, Le château de Saint-Cénéri, Bull. Soc. Hist. et Arch. de l'Orne, t. 86, 1968, pp. 22-34.

(56) R. JouAnne, Pages d'histoire. L'Orne combattante, ed. Alençon. 2 oct. 1960 ; Abbé Persignan, Saint-Cénéri-le-Gérei, ses souvenirs, ses monuments. Le Mans, 1865 ; H. PASTOUREAU, op. cit., note 55. Bibl. Nat. ms. lat 11055. Cartulaire de l'abbaye de Saint-Evroul ; chartes $n^{\circ} 42$ et 52. 
également de "tours plantées sur les bords du précipice" à l'Est du château ; malheureusement il n'en reste pratiquement aucune trace, si ce n'est, près de la seconde motte, un espace grossièrement quadrangulaire qui pourrait relever l'emplacement de l'une d'elles. A l'intérieur de l'enceinte, le cadastre distingue nettement deux parcelles, l'une appelée "le château» sur laquelle ont été découvertes des structures en maçonnerie, l'autre abritant «le donjon».

La chapelle castrale est plusieurs fois mentionnée dans des textes du XIII ${ }^{\mathrm{e}}$ siècle. En 1223, Gervais de Saint-Céneri accorde 25 sous en rente à l'église de Saint-Céneri et 5 sous au prieur du lieu pro recompensensatione capelle de castello Sancti Serenici. Cette donation est confirmée en 1250 par Guillaume III de Saint-Céneri. L'oratoire est situé sur un monticule près de l'entrée principale, au Sud du château. Il a fait l'objet de fouilles au XIX ${ }^{\mathrm{e}}$ siècle (57). La base des murs est encore visible; épais de $60 \mathrm{~cm}$ environ, ils enferment une superficie intérieure de $14,50 \mathrm{~m}$ sur $5,50 \mathrm{~m}$. La moitié de l'espace a été fouillé : plusieurs squelettes ont été exhumés, orientés Nord-Ouest-Sud-Est, comme la chapelle. Cinq sépultures avec les avants-bras croisés sur la poitrine ont été mises à jour. Auprès de trois d'entre elles, on a retrouvé des débris de vases et de charbon de bois... Les deux autres avaient les côtés maçonnés. A la tête de l'une d'elle, une pierre était posée à chant. A côté de ce squelette, reposaient des fragments de crâne et de mâchoire d'enfant. Outre ces sépultures, une douzaine de crânes et des ossements ont été découverts, éparpillés dans l'angle du bâtiment. Un boulet de pierre, un fer de flèche et deux pièces de monnaie furent également recueillis.

Le dispositif de la fortification de Saint-Céneri évoque celui des châteaux de Foulques Nerra (58), où on rencontre également une motte de couverture, un donjon et un bâtiment résidentiel distinct. Le fait est d'autant plus intéressant à souligner qu'il concorde avec nos sources écrites qui attestent l'influence angevine sur la forteresse.

\section{f) La Roche d'Igé (la Roche Mabille)}

Le château de la Roche d'Igé resta peu de temps aux mains des Géré. Vers 1059-1060, Robert Géré, en rébellion contre Guillaume le Bâtard, le fortifia « avec l'aide des Angevins ». La forteresse passa aux Bellême après la disgrâce des Géré et prit le nom de la Roche Mabille.

Le site, culminant à $254 \mathrm{~m}$ d'altitude, domine la vallée du Sarthon. Ses structures recouvertes en partie par la végétation sont complexes. D'après G. Louise, le site

(57) P. Barret, Les fouilles de Saint-Cénéri, Bull. Soc. Hist. et Arch. de l'Orne, 1890, pp. 265-68.

(58) G. Fournier, Le château dans la France médiévale, Paris, 1978, pp. 69, 76: O. Gulllot, Le comte d'Anjou et son entcurage au Xt' siècle, Paris, 1972, t. 1, p. 25. 285, t. 2. pp. 35-36. 
semble présenter trois enceintes successives concentriques : une plate-forme sommitale, aujourd'hui nivelée et deux enceintes en pierre et en terre sur les pentes (59).

$\mathrm{Au}$ total, les châteaux de la famille Géré offrent une assez grande diversité typologique. L'analyse de ces différentes forteresses cadre avec l'hypothèse selon laquclle «l'enceinte représenterait une résidence fortifiée quelque peu traditionnelle... Il ne serait pas étonnant de la voir aux mains de grands seigneurs fidèles aux princes", alors que le contexte de la motte "est souvent celui d'une période de troubles où l'autorité publique rencontre de multiples difficultés : désordres accompagnant des successions, usurpations ou accaparement de terres nouvelles et lointaines, constructions illicites...»(59 bis). Echauffour et Montreuil-l'Argillé furent inféodés à Giroie, vassal du duc. La construction de Montaigu et de Saint-Cénéri eut lieu à l'époque où les Bellême et les seigneurs de Mayenne se disputaient cette région frontière.

L'intérêt des châteaux ne se limite pas à l'étude de leur typologie, ils furent aussi un des éléments moteurs de l'organisation sociale et du peuplement au Moyen Age.

\section{Les bourgs}

On relève dans la baronnie de Saint-Céneri l'existence de plusieurs bourgs sur lesquels notre documentation demeure lacunaire. Trois d'entre eux sont des bourgs castraux (Saint-Céneri, Echauffour, Montreuil-l'Argillé). Il existait peut-être un bourg rural à Verneusses (un document de 1270 atteste l'existence d'une maison en bourgeoisie dans ce village, qui par ailleurs possédait une foire). Le bourg sur lequel nous sommes le mieux informé est celui de Saint-Evroul, il s'agit d'un bourg monastique. Bien qu'il ne fasse pas partie de la baronnie de Saint-Céneri, nous y ferons souvent référence.

La datation de ces agglomérations est difficile à établir, nous ne disposons en effet d'aucune charte de fondation. Les bourgs de Montreuil-l'Argillé et de SaintEvroul sont attestés dans le milieu $\mathrm{du} \mathrm{XI}^{\mathrm{e}}$ siècle. Au début des années 1050 Guillaume de Montreuil donna à l'abbaye de Saint-Evroul un bourgeois (burgensem). A Montreuil-l'Argillé, peu après vers 1056-57, un certain Ansquetil du Noyer céda au monastère un tiers du bourg d'Ouche (Saint-Evroul) qu'il tenait de son père. En revanche la datation des autres bourgs est malaisée. Le premier bourgeois d'Echauffour connu est cité en 1247. Nous n'avons aucune mention antérieure à cette date pour le bourg d'Echauffour. Orderic Vital y fait peut-être allusion quand il relate que l'abbé Mainier est né dans le castellum d'Echauffour au milieu du $\mathrm{XI}^{\mathrm{e}}$ siècle. Comme nous l'avons vu plus haut, un seul document, daté de 1270, atteste un bourg éventuel à Verneusses. En l'absence de fortification médiévale directement en rapport avec la localité, il s'agirait d'un bourg rural. Il faut attendre 1389 pour trouver la première

(59) Orderic VITAL, Histoire Ecclésiastique, II, 72-73 ; G. Louise, op. cit., note 2, p. 948.

(59 bis) Colloque de Caen 1980 : les fortifications de terre en Europe occidentale du X $\mathrm{C}^{\mathrm{c}}$ au XIII $\mathrm{X}^{\mathrm{c}}$ siècle. Archéologie médiévale, t. XI, 1981, p. 50. 
référence explicite de bourgeois et de bourgeoisie à Saint-Céneri, mais nous pouvons avancer cette date puisque la "ville » de Saint-Céneri élit deux " envoyés » aux Etats Généraux de 1308. Au XII ${ }^{\mathrm{c}}$ siècle, Orderic Vital qualifiait Saint-Céneri de municipe (60).

Les études faites sur ce sujet montrent que le bourg est un phénomène du $\mathrm{XI}^{\mathrm{e}}$ siècle (61). Dans les cas qui nous intéressent au moins deux de ces agglomérations remontent à cette période (Montreuil-l'Argillé, Saint-Evroul). Plusieurs des habitats que nous allons étudier se sont développés autour d'un château ou d'une abbaye. Ces éléments eurent une grande influence sur la topographie de la localité.

\section{a) Topographie des bourgs}

\section{Châteaux et bourgs}

Le bourg de Montreuil-l'Argillé offre un cas intéressant. G. Fournier a remarqué que souvent les châtelains ont implanté " un village inclus dans une ligne de défense avancée qui a souvent été une basse-cour extérieure et spécialement aménagée à cet usage " (62). Nous avons signalé l'existence possible d'une basse-cour de grande dimension à Montreuil-l'Argillé. Il est probable qu'une partie du bourg ait été bâtie dans cette basse-cour le long de la voie antique et de la Guiel. La rue qui passe au pied du château portait le nom de "rue aux Anges " (aujourd'hui, rue de la Libération), il s'agit vraisemblablement du vicus as Angiers signalé en 1316 à propos de la vente d'une rente sur une maison et une pièce de terre sises à Montreuil-l'Argillé entre ce vicus et la Guiel (63). Le reste de l'agglomération s'est développé de l'autre côté de la rivière, autour de deux axes : la rue Saint-Jacques avec son prolongement rue du Pont, qui reprend le tracé de la voie romaine, et la rue Grande qui conduit jusqu'à l'église.

Le lien entre le château et le bourg apparaît moins organique à Echauffour qu'à Montreuil-l'Argillé, peut-être en raison des profondes transformations que connut le château d'Echauffour. Le bourg s'étend au pied de la forteresse et le long de la route de L'Aigle à Sées qui semble avoir été le seul axe déterminant dans la croissance de l'agglomération.

(60) Montreuil-l'Argillé : Orderic VITAL, Histoire Ecclésiastique, Il, 37. Saint-Evroul, Ibidem, II, 60. D’après L. MUSSET, ce bourg existait peut-être avant la restauration de l'abbaye. Voir L. MUSSET, peuplement en bourgade et bourgs ruraux en Normandic, Cahiers de civilisation médiévale Xr'-XIIr" siècles, IX $^{\mathbf{c}}$ année, $\mathrm{n}^{\circ} 2$, avril-juin 1966, pp. 177-208; Echauffour, Querimonia Henrici de Avaugor, R.H.G.F., XXXIV, pp. 729-30 ; Orderic VITAL, II, 127; Verneusses, Archives de l'Orne, H 738 ; Saint-Céneri, Archives Nationales R 5 386, fol. 338 ; G. PICOT, Documents relatifs aux Etats Généraux et assemblées réunies sous Philippe le Bel, Rouen 1901, pp. 600-601.

(61) A. DeBOrd, Les bourgs castraux dans l'Ouest de la France : Flaran I : châteaux et peuplements en Europe occidentale du $x^{\circ}$ au XVIII' siecle. Auch 1979, pp. 57-73, E. ZadORA RıO: Bourgs castraux et bourgs ruraux en Anjou aux $\mathrm{XI}^{\mathrm{C}}$ et XII" siècles, Flaran I, pp. 173-179.

(62) G. Fournier, op. cit., note 58, p. 177.

(63) Archives de l'Orne H 742. 
A Saint-Céneri, l'agglomération s'est construite aux abords immédiats de la fortification, près de son entrée principale, au Sud. Cette proximité s'avérait d'autant plus nécessaire que Saint-Céneri fut souvent au premier plan d'événements militaires.

Dans ces trois cas, le château représente donc un facteur de cristallisation du peuplement. Un autre élément, ecclésiastique celui-là, cut des effets voisins.

\section{Eglises et bourgs}

Nous devons en premier lieu nous arrêter sur le bourg de Saint-Evroul. Il ne s'agit pas d'un bourg castral, mais d'une agglomération qui s'est développée à partir d'un monastère. L'abbaye joue alors un rôle voisin de celui du château, et accorde une protection (spirituelle celle-là) aux habitants du bourg. L'église paroissiale, située sur l'autre rive de la Charentonne, n'eut aucune influence sur le développement du village.

Fréquemment, le seigneur fondait une église, une collégiale ou un prieuré pour donner de l'importance à la localité née autour du château. Nous avons vu que Giroie a implanté plusieurs églises. La plupart sont situées dans des paroisses où, par la suite, un bourg est attesté. Il est donc intéressant d'envisager la relation qu'il peut y avoir entre bourgs et églises. On distingue différents cas de figures :

A Montreuil-l'Argillé, l'église est distante de $800 \mathrm{~m}$ du château. Autour de l'oratoire le « village de l'église » s'est développé sans jamais atteindre l'importance de l'agglomération castrale. Ce type d'habitat s'apparente aux villages doubles souvent observés en France. Si l'on s'en tient au récit d'Orderic Vital l'église dédicacée à Saint Georges fut fondée après l'oppidum; le nom de Monasteriolum suggère pourtant qu'une implantation ecclésiastique existait déjà auparavant. Il est probable que, outre l'aspect de juridiction ecclésiastique, étudiée dans notre première partie, Giroie I $^{\text {er }}$ ait construit l'église en vue d'étoffer le peuplement du chef-lieu de sa châtellenie de Montreuil-l'Argillé. En 1050, ses fils et petits-fils donnèrent à Saint-Evroul l'église, les dîmes du tonlieu et des autres coutumes, ainsi que trois fours.

Le cas d'Echauffour diffère quelque peu de celui de Montreuil-l'Argillé, l'église Saint-André est distante de $1,5 \mathrm{~km}$ du château et a été le noyau d'une seconde agglomération. Jusqu'au siècle dernier, on distinguait le village de Saint-Andréd'Echauffour du bourg d'Echauffour qui s'était formé au pied du château; aujourd'hui, les deux bourgades se nomment respectivement Echauffour et le Vieil Echauffour.

Malgré la distance relativement importante qui sépare les bourgs castraux et les églises à Montreuil-l'Argillé et à Echauffour, nous n'avons aucune mention de chapelle castrale ou d'oratoire situé près des châteaux.

A Saint-Céneri-le-Gerei, l'implantation religieuse est très ancienne; SaintCéneri y fonda un monastère au $\mathrm{VI}^{\mathrm{e}}$ siècle, plusieurs sarcophages ont été découverts 
notamment dans le cimetière. Le couvent fut détruit au $\mathrm{IX}^{\mathrm{c}}$ siècle par les Normands (64). Les Géré fondèrent un prieuré à l'extrémité de la boucle que forme la Sarthe. En 1050 Robert I ${ }^{\text {er }}$ Géré donna à Saint-Evroul l'église et la dîme de Saint-Céneri ainsi que la moitié d'un verger, et les pêcheries dans la Sarthe. Les textes $\mathrm{du} \mathrm{XII}{ }^{\mathrm{e}}$ siècle reprennent et complètent cette donation. Le premier texte, signalant un prieur à Saint-Céneri, date de la fin du XII ${ }^{\mathrm{e}}$ siècle. La toponymie de toute la partie sud de la localité atteste l'implantation monastique. Saint-Céneri représente un type connu de bourg castral à structure bipolaire organisé autour du prieuré et du château.

Le château, l'abbaye, l'église sont donc autant de facteurs qui contribuèrent à fixer la population dans un endroit choisi par le seigneur. Nous allons voir maintenant les composantes plus directement liées au bourg en lui-même.

\section{Les autres éléments du bourg : rues, lotissements, halles}

En dehors des grandes villes, peu de rues médiévales sont attestées. J.P. Legay constate que «l'apparition d'un nom concrétise l'importance prise par une rue, la densité de son peuplement et l'intérêt de son rôle de desserte ou sa fonction économique, une urbanisation achevée s'il s'agit d'un chemin rural récemment absorbé par l'extension citadine ».

Nous connaissons au moins quatre noms de rues à Saint-Evroul : en 1230 Guillaume des Astelles donne à l'abbaye d'Ouche deux sous tournois que lui versait Jean Pavinard au sujet de sa maison située in rua de Bocquenchay. D'autres documents mentionnent des maisons sises "in villa Sancti Ebrulfi, in vico de Eschaufoyo ». En 1338 un certain Jean Guiam dit Rubeschel prend en fief une oseraie située entre la chaussée du vivier Saint-Père et la rue du Pont. Enfin, comme nous l'avons vu plus haut, une rue Lambarde est citée à Saint-Evroul au $\mathrm{XV}^{\mathrm{e}}$ siècle.

Ces indications montrent une progressive urbanisation des abords immédiats de certaines voies de communication, qui se traduit par l'abandon de périphrases $\mathrm{du}$ genre « chemin de Saint-Evroul à Bocquencé », au profit d'appellations plus courtes, ici la rue Bocquencé. Ces textes suggèrent également une relative importance de l'axe Nord-Sud (rues de Bocquencé et d'Echauffour) du bourg au XIII ${ }^{\mathrm{e}}$ siècle, et l'existence d'une activité économique assez conséquente pour justifier la présence d'une «rue Lambarde ». Une charte de la fin $d u X V^{e}$ siècle évoque la nostalgie de cette opulence ruinée par la Guerre de Cent Ans, quand, parlant d'héritages sis au carrefour des halles, il rapporte " qu'ils estoient de bonne valeur, lorsque la dite ville et bourgeoisie de Saint-Evroul lestoit fort édiffiée et y affluaient de grandes marchandises et sont tournés en grand ruyne et decadence, à l'occasion des guerres, ladite ville a esté détruite, et encore dont de petite valeur $»$.

(64) Th. Mercier, Saint-Cénéri-le-Gérei, découverte d'un sarcophage, Bull. Soc. Hist. Archéologie de l'Orne, t. 85, 1967, pp. 136-137 ; H. PASTOUREau, Légende et Histoire de Saint-Cénéri, de son abbaye, de ses reliques et de son culte, Bull. Soc. Hist. Arch. de l'Orne, nº 83, 1965, pp. 3-38. 
La seule rue médiévale attestée à Montreuil-l'Argillé est le vicus as Angiers dont nous avons parlé plus haut. Nous ignorons d'où vient ce nom; il est possible qu'il porte le patronyme d'une famille domiciliée à cet endroit, la maison et la terre situées près de ce vicus sont tenues par la veuve du défunt Richard Langière (65). La toponymie actuelle des rues de Montreuil-l'Argillé reflète probablement les appellations médiévales (ex : la rue Grande, la rue Saint-Jacques). Il faut également notcr la présence d'une « rue aux Juifs». Le cas est d'autant plus intéressant qu'un certain Joce Juif de Montreuil (Joceto Judeo de Monsterolio) est attesté à la fin du $\mathrm{XIII}^{\mathrm{e}}$ siècle (66).

L'étude des rues dans des bourgs qui, somme toute restèrent modestes, est rendue difficile par le manque de document: elle peut cependant donner des indications précieuses sur l'évolution et l'importance de la localité. Les indices pour chiffrer la population d'un bourg restent en effet rarissimes : on sait seulement qu'en 1136, le bourg de Saint-Evroul comptait au moins 84 maisons (67). Les rôles de fouages sont tardifs et incomplets; le plus ancien que nous ayons date de 1317, ce sont "les deffaus de fouage" de la vicomté de Trun. Ce document donne 29 sous (= 29 feux) pour Montreuil-l'Argillé ; 31 sous pour Echauffour ; mais ces chiffres ne sont pas utilisables car il s'agit d'un relevé complémentaire du compte principal du fouage de 1314 (disparu) (68).

Les quelques textes qui nous renseignent sur les emplacements et les maisons demeurent très imprécis. Les termes employés varient : ceux qui reviennent le plus souvent sont les mots : domus cum orto/horto; ou domus cum gardino, parfois cum clauso. L'hortus désigne le jardin mais aussi l'emplacement : une charte de 1282 parle d'un hortus vel area in villa Sancti Ebrulfi appartenant à Guillaume le Mercier, bourgeois de Saint-Evroul. L'expression area se trouve dans plusieurs autres textes. Il désigne souvent un emplacement destiné à être habité ou bâti. Ainsi, à SaintCénéri, la toponymie révèle un ensemble de parcelles nommées « les aires ». Un aveu de 1598 rapporté à la baronnie d'Echauffour donne une idée de ce que pouvait être un lotissement en bourgeoisie: "une maison à quatre aistre... (dont une sert de grange et une autre de cellier) avec cour et jardin, le tout contenant environ 30 perches... » (69), à cela s'ajoutaient d'autres biens tenus en bourgeoisie. Le cadastre napoléonien conscrve rarement des traces d'allotissement médiéval, il semble y en avoir eu à Montreuil-l'Argillé entre la Gueil et la rue des Anges (voir plan du château). Il apparaît plus clairement à Saint-Cénéri, notamment auprès de deux axes parallèles situés entre "le clos de la Maison de Dieu» et «les aires». Nous

(65) Sur les rues : Cartulaire de Saint-Evroul, B.N., ms. lat $n^{\circ} 11055, n^{\circ} 317$ ms. lat $n^{\circ} 11057, n^{\circ} 193$, 203 ; Archives de l'Orne H 576, 596 t, 1742; Voir J.P. LEGAY, La rue au Moyen Age, Rennes, 1984.

(66) Archives de l'Orne H 739, H 740.

(67) Orderic Vital, Histoire Ecclésiastique, V, 61-62.

(68) M. NORTIER, Recherches sur l'étude, les subdivisions et la population des vicomtés de Caen et de Falaise au XIV ${ }^{\mathrm{c}}$ siècle. B.S.A.N., 54, 1957-58, pp. 101-145.

(69) Archives de l'Orne 2 E 55. 
avons bien peu de renseignements sur les maisons elles-mêmes. Seul un texte du $\mathrm{XIV}^{\mathrm{c}}$ siècle concernant Saint-Céneri parle d'une maison "édifiée tant de pierre comme de boys $"$.

Les halles occupent une place importante dans la topographie des bourgs, elles sont pourtant rarement mentionnées. Un document de 1345 parle du "chemin des hales » à Saint-Evroul. Celles d'Echauffour sont également connues par un acte de la fin du XIV siècle : "présents... à la forge et es halles pour tenir les plez de la forest ". Elles tombèrent peu à peu en ruines : un aveu du XVIII ${ }^{\mathrm{c}}$ siècle cite encore le " chemin des vieilles halles ", mais celles-ci n'apparaissent plus dans le cadastre de 1811. Aucun document médiéval n'atteste les halles de Montreuil-l'Argillé, mais l'aveu du marquis d'Echauffour indique qu'en 1587 les officiers de la juridiction royale de Montreuill'Argillé (c'était une vicomté) eurent la permission « de faire construire un pretoire et cohue a icelui attaché aux halles de Montreuil ». Elles sont encore visibles sur le cadastre, sises au carrefour des deux axes principaux de la localité, mais ont disparu depuis(70). Un texte de 1389 situe une maison par rapport aux cohues de Saint-Céneri, la topographie des lieux en a gardé les traces.

En dehors de leur topographie, les bourgs se distinguent aussi par leurs privilèges, notamment par la dotation de foires et marchés.

\section{b) Foires et marchés}

L'aveu de 1681 mentionne six foires dans les seigneuries d'Echauffour et de Montreuil-l'Argillé. Les deux qui se tiennent dans l'honneur d'Echauffour ne sont pas situées dans le bourg lui-même : l'une d'elles a lieu à la " chapelle Saint-Denis », le jour de la Saint-Denis d'octobre (9 octobre); l'autre se tient à Planches le jour de Notre-Dame de septembre ( 8 septembre) pour laquelle «le prieur de Planches est tenu de faire chevauchée avec son surply, ayant un oiseau sur le poing, pour m'en donner du plaisir ». La foire de Planches est attestée très tôt par nos sources. Vers 1040-1050, Guimond de Moulins-la-Marche donne à Saint-Père de Chartres locellum Sanctae Mariae de Plancis... cum decima quae ad locum pertinet et suburbio et teloneo et fera, eam scilicet partem quae ad me pertinet; cette donation est ensuite confirmée vers 1063-1066 par son beau-fils Guillaume. A la fin du XI siècle, Roger de Montgommery concède à Saint-Evroul apud Excalfoium... decimamque nundinarum de Plancis de parte mea.

Ces textes amènent plusieurs réflexions : d'une part la foire de Planches est l'une des plus anciennes connue en Normandie; le droit de foire cessa certes assez tôt d'être un monopole ducal, mais il faut surtout attendre le règne de Robert Courteheuse pour qu'il soit massivement octroyé. D'autre part, il semble bien que les

(70) Sur les halles: Cartulaire de Saint-Evroul ms. lat 11057, nº 216; Archives de l'Orne H 796, 2 E 55 ; Archives Nat., p. 867. 
seigneurs d'Echauffour et de Moulins-la-Marche se partagent la foire : dans les textes chacun précise qu'il en a seulement une partie. Le geste du prieur de Planches (dépendant de Saint-Père de Chartres) au XVII ${ }^{\mathrm{e}}$ siècle, symbolise cet ancien état de choses. Le village de Planches (qualifié de suburbium au XI ${ }^{\mathfrak{c}}$ s.) est séparé en deux par la Risle: l'Est, où se trouve l'église paroissiale, dépendait de la seigneurie de Moulins-la-Marche, l'Ouest relevait de la seigneurie et de la paroisse d'Echauffour.

Un document du XV $\mathrm{XV}^{\mathrm{c}}$ siècle donne une idée de l'activité de cette foire. En 1412, l'abbé et le couvent de Saint-Evroul « estoient plaintifs que Perrin Toustain de la ville d'Echauffou, comme cueilleur et fermier de la coustume de la foire de Planches derrainement passée, avoit print et receu de Thomas Godehent dit Molet leur famillier la somme de quatre deniers tournois de coustume de l'achat de certains cuirs qu'il avoit achetés à l'active foire pour leur user ». Comme le montre ce texte, la foire de Planches donnait lieu à la perception d'une coutume (dont les moines auraient dû être exempts, ce qui motive le procès). A l'instar de beaucoup d'autres foires, le mode de gestion en était l'affermage (71).

Les aveux de 1681 signalent quatre foires dans la seigneurie de Montreuill'Argillé : deux se tiennent dans le bourg castral, le premier lundi de carême et le jour de la sainte-Catherine (le 25 novembre) ; une troisième a lieu à Verneusses, le jour de Notre-Dame de septembre (le 8 septembre) et la quatrième à Monnai à la SaintSauveur (9 novembre). Malheureusement nous n'avons que des informations fragmentaires : seule la copie du XVII ${ }^{\mathrm{c}}$ siècle d'un acte de 1456 indique que Saint-Evroul percevait vingt livres de rente sur la foire de Montreuil-l'Argillé et quatre livres sur celle d'Echauffour. Aucun document ne parle des foires de Verneusses et de Monnai. A Saint-Evroul, la foire saint-Nicolas est mentionnée dans un faux acte de 1128 ; au $\mathrm{XIV}^{\mathrm{c}}$ siècle, elle était également affirmée (72).

Les marchés apparaissent dès 1172 à Montreuil-l'Argillé et Saint-Céneri, en 1219 à Echauffour et en 1298 à Saint-Evroul. Ils avaient lieu le mercredi à Montreuil-l'Argillé, le vendredi à Saint-Evroul et le dimanche à Saint-Céneri. Tout comme les foires, les marchés donnaient lieu à la perception de coutumes. Elles firent l'objet d'accords entre les barons de Saint-Céneri et les religieux, ainsi les hommes de Saint-Evroul vivant dans le fief de Montreuil-l'Argillé qui vendaient quelque chose dans cette villa ou dans son district (baillia) payaient la coutume aux moines. Il en était de même pour les étrangers qui achetaient ou vendaient dans la terre des moines, sauf le mercredi propter mercatum Mosterelli. Il était prévu que les marchands (mercatores) de la terre des moines et les bordiers paient au marché la coutume de ce qu'ils vendaient ou achetaient le mercredi, sauf en ce qui concerne leur nourriture et leurs vêtements ; mais les autres jours eux et les vavasseurs ne payaient la coutume

(71) Sur la foire de Planches: Archives Nationales, p. 867, M. FaurouX, L. Musset, Recueil des Actes des ducs de Normandie 911-1066, Caen, 1961, $\mathrm{n}^{\circ}$ 117, 225; Orderic VITAL, Histoire Ecclesiastique, II, 413, Archives de l'Orne H 885 ; Voir aussi : L. MuSSET, Foires et Marchés en Normandie à l'époque ducale. Annales de Normandie, mars 1976, pp. 3-23.

(72) Gallia Christiana, XI, instr, col. 207, Cartulaire de Saint-Evroul B.N., ms. lat $n^{\circ} 11055, \mathrm{n}^{\circ} 665$. 
qu'aux moines. A Echauffour, lorsque les hommes de Saint-Martin de Sées venaient vendre ou acheter au marché, ils devaient payer la coutume comme les autres; ceux qui habitaient le domicile des moines en étaient exempts (73).

Les châteaux et les bourgs ont visiblement représenté les composants principaux de la maîtrise du sol ainsi que du pouvoir que les barons de Saint-Céneri détenaient sur leurs hommes. Cette maîtrise n'était pas seulement celle du lignage châtelain mais également celle du groupe aristocratique qui l'entourait.

\section{LE GROUPE ARISTOCRATIQUE AUTOUR DES GÉRÉ}

L'étude d'un lignage châtelain et de sa seigneurie permet d'aborder une catégorie qui reste mal connue en Normandie : la petite aristocratie, ceux qui ne détiennent pas de châteaux. Bien des questions se posent sur l'origine et l'évolution de ce groupe, sur les relations qu'entretiennent ses membres avec le châtelain. Le terrain à défricher demeure immense. Les quelques observations que nous apportons ici à propos des vassaux des Géré sont loin de pouvoir répondre à ces questions.

\section{Le groupe aristocratique au $\mathrm{XI}^{\mathrm{e}}$ siècle.}

Les vassaux des Géré apparaissent rarement individuellement avant la fin du $\mathrm{XII}^{\mathrm{c}}$ siècle, si ce n'est pour souligner un exploit ou une perfidie de l'un d'entre eux, comme l'assassinat d'Ernaud d'Echauffour par son chambrier Roger Goulafre, à l'instigation de Mabille de Bellême (74).

Dans le rapide portrait qu'il brosse des fils de Giroie l'Ancien, Orderic Vital montre non seulement qu'ils s'adonnaient tous aux exercices militaires, y compris le clerc de la famille qui reçut le nom de "Maucouronné », mais que de jeunes guerriers les assistaient. Ainsi Ernaud Géré se blessa mortellement en s'exerçant avec un fortis juvenis et son frère Hugues fut tué par un écuyer (armiger) alors qu'ils maniaient la lance à Saint-Germain-d'Echauffour (75). Il existe donc bien autour des Géré un

(73) Sur les marchés: Cartulaire de Saint-Evroul; B.N. ms. lat $11055, \mathrm{n}^{\circ} 22$, Cartulaire de Saint-Martin de Sées; Archives de l'Orne H 938, fol. 116, Archives de l'Orne H 581 ; Archives Nat., p. 867.

(74) Orderic VITAL, op. cit., note 3, II, 107.

(75) Orderic VITAL, op. cit., note 3, II, 25-26, 29. 
compagnonnage aristocratique de guerriers non adoubés (armigeri) et de jeunes (juvenes) non encore établis (76).

L'origine des lignages de la petite aristocratie gravitant autour des Géré au $\mathrm{XI}^{\mathrm{c}}$ siècle est mal connue, trop peu d'indices nous sont en effet parvenus pour mener une enquête prosopographique. Il convient cependant de faire quelques remarques :

- En premier lieu, on distingue un groupe constitué par des chevaliers apparentés au lignage châtelain : ainsi les Montreuil/Réville descendent probablement d'un Giroie bâtard de Foulques de Montreuil ; Orderic Vital cite également un certain Guillaume le Prévost, miles egregius possessionné à Saint-Aquilin d'Augerons qui est parent de Guy Bollein lui-même pronepos de Giroie ${ }^{\text {er }}$ (77).

- D'autre part, il est possible que parmi les membres de cette petite aristocratie il y ait eu des éléments d'une catégorie peu connue en Normandie: les pagensis equites. Aucun vassal des Géré n'est cité comme tel dans nos sources, mais nous savons qu'il en existait dans le Pays d'Ouche. Orderic Vital rapporte en effet un miracle qui eut lieu avant la fondation de Saint-Evroul mettant en scène un certain Gumfoldus de Touquettes pagensis eques (78). L'expression est employée par le moine d'Ouche dans un autre passage de l'Histoire Ecclésiastique : à la mort de Guillaume le Conquérant, c'est un pagensis eques nommé Herluin qui prit à sa charge une partie des préparatifs aux funérailles du duc (79). Peut-on rapprocher cette catégorie des pagenses méridionaux des $\mathrm{XI}^{\mathrm{e}}$ et $\mathrm{XII}^{\mathrm{c}}$ siècles étudiées par $\mathrm{E}$. Magnou Nortier? On sait en effet que les pagenses du haut Moyen Age étaient des notables ruraux et des agents du fisc étroitement subordonnés au comte, caractères qu'ils conservent en Biterrois aux XI ${ }^{\mathrm{e}}-\mathrm{XII}^{\mathrm{e}}$ siècles (80). La question mériterait d'être approfondie pour la Normandie.

\section{Evolution du groupe aristocratique (fin $\mathrm{XII}^{\mathrm{e}}$ et début XIII ${ }^{\mathrm{e}}$ s.)}

Les lignages vassaux des barons de Saint-Céneri apparaissent plus clairement à partir du dernier tiers du XII ${ }^{c}$ siècle. Après une lacune documentaire d'une trentaine d'années, nos sources deviennent plus abondantes; elles permettent de suivre l'évolution de l'aristocratie de la baronnie jusqu'à la fin du XIII ${ }^{\mathrm{e}}$ siècle. Trois documents offrent une base de départ pour l'étude de cette évolution : l'enquête de 1172 sur les fiefs qui révèle que Guillaume II de Saint-Céneri a une vingtaine de chevaliers à son service ; la même année une confirmation des biens de l'abbaye de

(76) G. Duby, «Les jeunes dans la société aristocratique », Hommes et structures du Moyen Age, Paris, 1976, pp. 213-225.

(77) Orderic VITAL, op. cit., note 3, II, 36, 77.

(78) Ibidem, III, 112-113.

(79) Ibidem, III, 258.

(80) E. Magnou Nortier, Les pagenses, notables et fermiers du fisc durant le haut Moyen Age. Revue belge de Philologie et d'Histoire, LXV, 1987, 2, pp. 237-58. 
Saint-Evroul donne les noms d'une dizaine d'entre eux; enfin, vers 1172-81, une charte d'Arnoul, évêque de Lisieux révèle pour la première fois l'existence de sires de village dans des paroisses dépendantes de l'honor de Montreuil-l'Argillé (81). Par la suite notre documentation s'étoffe pour culminer dans le premier tiers du XIII ${ }^{\mathrm{c}}$ siècle.

On peut faire plusieurs remarques quant à l'évolution du groupe aristocratique établi dans la baronnie de Saint-Céneri à partir de l'observation de certains phénomènes :

\section{a) Les premières chartes}

Jusqu'à la fin du XII ${ }^{c}$ siècle nous ne connaissons aucune charte provenant d'un lignage de la baronnie. Lorsque les vassaux des Géré apparaissent dans les documents diplomatiques, c'est toujours collectivement et dans une charte donnée par le châtelain, le roi, ou le pouvoir ecclésiastique. C'est dans les dernières années du $\mathrm{XII}^{\mathrm{e}}$ siècle et dans le premier quart du XIII ${ }^{\mathrm{e}}$ siècle (entre 1190 et 1225) que la plupart des lignages émettent leurs premières chartes, indépendamment du châtelain.

Il serait intéressant de disposer des originaux scellés pour voir si dans le même temps la petite aristocratie se dotait d'armoiries ou de signes distinctifs de son état. Malheureusement nous disposons seulement de deux sceaux : celui de Robert de Longpont, au début du XIII ${ }^{\mathrm{e}}$ siècle, représentant un écu avec deux léopards et celui de Guillaume d'Echaumesnil, plus tardif (1298) évoquant une quintefeuille (82).

\section{b) Les titres}

Jusqu'à la fin du XII ${ }^{\mathrm{c}}$ siècle, on ne remarque aucun terme pour qualifier individuellement les vassaux des Géré. Le mot miles est rarement employé au singulier, quand cela se produit, il est accompagné d'un possessif marquant la dépendance de l'individu concerné. Encore une fois, le groupe aristocratique apparaît collectivement (milites).

A partir du dernier quart $\mathrm{du} \mathrm{XII}{ }^{\mathrm{c}}$ siècle, une évolution se dessine, les lignages affirment leur volonté de se distinguer, par le port de certains titres tels que :

- dominus : les premiers sires de village apparaissent dans nos sources vers 1172-1181 pour trois paroisses de l'honor de Montreuil-l'Argillé, Réville, Monnai, la Goulafrière. Même s'ils ne sont pas cités nommément, les sires appartiennent sans aucun doute aux lignages de Montreuil/Réville, de Monnai et Goulafre, c'est-à-dire trois des plus anciennes familles attestées autour de Montreuil-l'Argillé dès le milieu $\mathrm{du} \mathrm{XI}^{\mathrm{e}}$ siècle. Sur la seigneurie d'Echauffour, les domini de village sont cités plus

(81) R.H.G.F., XXXIII, p. 695 G, Cartulaire de Saint-Evroul, op. cit., n² 22 et 181 .

(82) Archives de l'Orne H 672 et $\mathrm{H} 581$. 
tardivement au début du XIII ${ }^{\mathrm{c}}$ siècle à Beaufay (1200) et Saint-Pierre-des-Loges (1214) ils sont contemporains de la plupart des autres sires de village repérés dans cette région du Pays d'Ouche. A partir de 1240, le titre se généralise et est porté par l'ensemble des détenteurs de fief ou de fraction de fief. Réservé aux châtelains au $\mathrm{XI}^{\mathrm{c}}$ siècle et pendant une bonne partie du XII siècle, le titre de dominus se dévalue rapidement à partir de la fin du XII siècle, porté d'abord par des lignages anciennement établis dans un village, puis par tout détenteur de fief ou de fraction de fief dans la seconde moitié du XIII ${ }^{\mathrm{e}}$ siècle.

- miles et armiger: employé exclusivement au pluriel pendant les $\mathrm{XI}^{\mathrm{c}}$ et $\mathrm{XII}^{\mathrm{e}}$ siècles pour désigner les vassaux des Géré, le terme de miles est employé individuellement à partir des dernières années du XII ${ }^{\mathrm{c}}$ siècle (la diffusion du titre suivant souvent d'assez près l'émission des premières chartes). Ce changement reflète sans doute la volonté des chevaliers de marquer leur appartenance à un ordre dans lequel on entrait après une cérémonie : l'adoubement. Tous les lignages ne pouvaient financer cette coûteuse cérémonie, ainsi voit-on se généraliser le terme "d'écuyer " (scutifer, armiger). Rare avant la première moitié du XIII ${ }^{\mathrm{e}}$ siècle pour les détenteurs de fief, le terme apparaît brusquement dans toutes les familles chevaleresques entre 1259 et 1270. L'adoption de ce titre montre la volonté de distinguer les fils de chevaliers ne pouvant être adoubćs. Le critère retenu est donc désormais la naissance. Cette évolution est très significative de la progressive mutation de l'aristocratie en une noblesse, en une "caste ouverte à ceux qui sont bien nés" (83). Il semble que cette mutation soit en cours autour de 1260 dans la région qui nous occupe.

\section{c) Les changements de nom}

Au cours du XIII ${ }^{\mathrm{e}}$ siècle et au début du XIV ${ }^{\mathrm{e}}$ siècle, un certain nombre de familles changèrent de nom et adoptèrent celui de leur fief ou de la paroisse dont ils étaient seigneurs. Le nombre de cas est réduit. Deux sont certains, les Montreuil/Réville (dans les années 1220), Robert de Montreuil, fils de Payen, se fait aussi appeler Robert de Réville; à la génération suivante, le lignage abandonna définitivement le nom de Montreuil. Pour les Saint-Martin/du Chesnay, c'est à la fin du XIIr ${ }^{\mathrm{c}}$ siècle que la substitution du nom du fief (le Chesnay) s'opère aux dépends du nom de la paroisse (Saint-Martin-de-Heugon) où celui-ci est situé. Un troisième cas (lignage de la Haie) montre que la substitution n'a pu s'opérer, le nom du fief de la Motte à Heugon n'a pu éclipser le nom du lignage (la Haie). Le dernier exemple est un cas particulier. A la suite d'un héritage tombé en quenouille, le mari de l'héritière prend son propre patronyme (Jean de Saint-Denis) soit celui de la paroisse dont il devient le seigneur (Jean de Beaufay), ses fils obtèrent pour ce dernier nom.

(83) G. DubY, "Situation de la noblesse en France au début du XIII" siècle », Hommes et structures du Moyen Age, Paris, La Haye, 1973, pp. 343-52. 
Le nombre réduit de ces cas observés ne permet pas d'en tirer de conclusion, peut-être peut-on cependant considérer que ce mouvement traduit un renforcement de l'assise seigneuriale sur le fief ou la paroisse.

\section{L'habitat}

Georges Duby et Gabriel Fournier ont souligné qu'à partir de la fin du $\mathrm{XII}^{\mathrm{e}}$ siècle les chevaliers transformèrent leurs demeures pour en faire des "maisons fortes " (84).

Les traces d'habitat aristocratique sont encore nombreuses dans le Pays d'Ouche. Malheureusement en l'absence quasi-totale de sources écrites médiévales, il faut bien souvent se contenter des éléments que nous livre l'observation sur le terrain et la toponymie. Nous avons relevé une dizaine de sites susceptibles d'avoir abrité un habitat chevaleresque au cours du Moyen Age, soit parce qu'ils sont attestés par des textes médiévaux, ou parce qu'un lignage y est attesté au cours de la période, ou car le site est le "chef »d'un fief connu dès le Moyen Age.

Seuls 3 sites sur 11 (soit $27,2 \%$ ) sont attestés avant le $X V^{c}$ siècle, encore ne s'agil-il que de mentions très vagues: masuagium, manérium (Réville, XIII ${ }^{\mathrm{e}} \mathrm{s}$.), plesseiceium (Beaufay fin XII ${ }^{\mathrm{e}} \mathrm{s}$.), domus (Tremont vers 1200) qui n'ont pas uniquement le sens d'habitat. La typologie de ces habitats reste difficile à établir faute de fouilles archéologiques et en raison de l'état des sites concernés. Pour la plupart, ces habitats ont été soit détruits (Réville, Saint-Pierre-des-Loges, La Motte Heugon, Tremont) soit remaniés postérieurement (Monnai, Beaufay, Bosc Hébert, le Chesnay, le Tremblay, le Plessis, Saint-Germain-d'Aunay). La plus ancienne construction encore debout est semble-t-il le manoir de Saint-Germain-d'Aunay, construit à la fin $\mathrm{du} X v^{\mathrm{c}}$ siècle et en partie remanié à la fin $\mathrm{du} X \mathrm{XI}^{\mathrm{c}}$ siècle.

On peut faire cependant quelques remarques:

- La plupart de ces sites sont fossoyés (8 sur 11 soit 72,7\%) à l'exception du Tremblay (le château actuel date du XVIII ${ }^{\mathrm{c}}$ s., entouré d'allées à la française), de Saint-Germain-d'Aunay, et du Plessis.

- Ces sites fossoyés ont souvent une forme plus ou moins quadrangulaire (Monnai, Beaufay, le Bosc Hébert, le Chesnay), plus rarement circulaire (Réville, Saint-Pierre-des-Loges) parfois difficiles à déterminer étant donné l'état du site (Trémont, la Motte Heugon, pour cette dernière les fossés sont très peu apparents, bien que la toponymie du site comporte une parcelle nommée les fossés).

- Quelques sites disposent d'éléments de défenses spécifiques (tour, échauguette). C'est le cas de Monnai (tour flanquée d'une échauguette), du Plessis (une tourelle), de Saint-Germain-d'Aunay (une échauguette) et peut-être de Réville (on y

(84) G. Duby, op. cit., note 83 ; G. Fournier, op. cit., note 58, pp. 210-215. 
distingue les ruines d'une construction en pierre qui pourraient bien être les bases d'une tour), soit quatre habitats $(36,6 \%)$. En revanche on ne relève aucune enceinte ni tour porche.

La situation de l'habitat par rapport à l'église du village varie de 300 à $3000 \mathrm{~m}$; de même, il ne semble pas qu'il y ait de sitcs topographiques particuliers. - Dernière remarque enfin, aucun fief auquel on peut rattacher ces habitats ne dispose de la haute justice.

Au total, il convient d'être très prudent sur la nature des habitats aristocratiques que nous venons de présenter. Maison forte? Maison basse? Considérant l'état actuel des sites présentés en l'absence de fouilles, il serait prématuré de conclure, d'autant plus que la distinction entre les deux a varié selon les époques, en fonction de l'emprise du pouvoir politique, de l'évolution des techniques militaires ou de la présence ou non de guerres (85).

\section{Un lignage de chevaliers : les Montreuil/Réville}

Il est possible, grâce en particulier au Cartulaire et au Chartrier de Saint-Evroul de suivre une douzaine de lignages vassaux des sires de Saint-Céneri, entre la fin du $\mathrm{XII}^{\mathrm{e}}$ et le milieu du XIV ${ }^{\mathrm{e}}$ siècle. Certaines de ces familles sont déjà attestées dès le $\mathrm{XI}^{\mathrm{e}}$ siècle. Il n'est pas question ici de les passer toutes en revue, il est néanmoins intéressant d'en approcher une qui, par certains aspects (ex. ses origines) occupe une place à part dans le groupe vassalique, mais qui par d'autres côtés semble assez représentative des changements que connaît la petite aristocratie en Pays d'Ouche à partir de la fin du XII ${ }^{\mathrm{e}}$ siècle.

La famille de Montreuil/Réville est, de loin la plus importante de l'honor de Montreuil-l'Argillé. Dans les listes de vassaux données par les confirmations de 1172 et de 1189-99, Giroie, puis Payen de Montreuil sont cités en premier, juste après les barons de Saint-Céneri, c'est également la seule lignée vassale où on retrouve l'anthroponyme de Geroius. La première démarche consiste donc à se demander d'où vient cette prééminence.

Il est probable que ce lignage descende des Géré eux-mêmes. D'après Orderic Vital, Foulques de Montreuil, fils de Giroie d'Ancien, eut deux bâtards, Foulques et Giroie. Après l'exil d'Ernaud d'Echauffour, Giroie demeura dans le Pays d'Ouche. Orderic raconte en effet que " Giroie, fils de Foulques de Montreuil » faisait partie des chevaliers qui spolièrent l'abbaye de Saint-Evroul après l'expulsion d'Ernaud d'Echauffour. A notre connaissance, il est le seul Géré resté dans la région, hormis le fils d'Ernaud, Renaud, placé au couvent d'Ouche après la mort de son père. A partir de 1061, les châteaux de Saint-Céneri et de la Roche Mabille furent confiés à

(85) La Maison forte au Moyen Age, Actes du colloque de Nancy, Pont-à-Mousson, 31 mars, 3 juin 1984 ; dir. M. Bur. Paris, CNRS, 1986. 
Roger de Montgommery, tandis que le duc installait une garnison à Echauffour. Aucun texte ne parle de Montreuil-l'Argillé. Nous pensons que Roger de Montgommery ou Guillaume le Conquérant en donnèrent la garde au fils bâtard de Foulques de Montreuil. C'était un moyen pour le duc d'évincer les héritiers légitimes sans rompre totalement le lien qui unissait les vassaux de la famille Géré à leurs anciens seigneurs (rappelons que presque toutes les familles vassalcs des Géré au milieu du $\mathrm{XI}^{\mathrm{c}}$ siècle apparaissent autour de Montreuil-l'Argillé.)

La configuration des fiefs de l'honor de Montreuil conforte cette hypothèse. Les de Montreuil/Réville tenaient le fief de Réville dont relevaient directement deux fiefs de haubert (la Goulafrière et Monnai), deux demi-fiefs ( Liesse au Sap André et le Tremblay à la Goulafrière), et un huitième de fief à Montreuil. Cette disposition se retrouve au niveau des droits ecclésiastiques: fin $\mathrm{XII}^{\mathrm{c}}$-début XIII ${ }^{\mathrm{c}}$ siècle, Payen de Montreuil reconnut tenir de Saint-Evroul le patronage de Saint-Léger de Réville et abandonna ce qu'il avait ou revendiquait sur les églises de la Goulafrière, de Monnai, de Ternant, des Essarts. Comme nous le voyons, cela couvrait une bonne partie de l'honor de Montreuil-l'Argillé. Il est donc très probable que cela reflète une situation antérieure consécutive à la fonction du lignage. L'emploi du prénom de Giroie au milieu du XII ${ }^{c}$ siècle perpétuait le souvenir d'un ancêtre illustre, le nom de Montreuil symbolisait l'attachement de la lignée au château.

L'implantation des de Montreuil à Réville pose un problème. Un autre lignage y était déjà établi au milieu du $\mathrm{XI}^{\mathrm{c}}$ siècle, en 1050 Herfred de Réville donna l'église Saint-Léger à l'abbaye d'Ouche. Avant 1077 Giroie d'Echauffour concéda au Bec Hellouin la pâture du moulin du Mesnil-Josselin (La Trinité du Mesnil-Josselin, paroisse réunie à Réville) ainsi que la rive et une acre et demie de terre qu'apporta Herfred de Réville. Il est possible que les descendants de Giroie aient obtenu ce fief à la suite d'une deshérence mais ce n'est qu'une hypothèse parmi d'autres.

Giroie de Montreuil cité avec les vassaux de Robert III Géré en 1172 est témoin dans une charte du seigneur de Pont-Echanfré. Son fils mieux connu, Payen de Montreuil apparaît également dans la confirmation de 1172 aux côtés des seigneurs de Montreuil, de l'abbé et des moines, il approuve et confirme les coutumes que Saint-Evroul devait avoir à Montreuil. C'est sans doute à lui et à son père que réfère la charte d'Arnoul, évêque de Lisieux, quand pour la première fois, elle parle des domini du village de Réville. Payen est mentionné ensuite à plusieurs reprises dans les Rôles de l'Echiquier. Entre 1189 et 1200 il est témoin de plusieurs chartes de Robert II de Meulan, comte de Beaumont-le-Roger, il est notamment cité en 1189 dans le contrat de mariage entre Galeran III fils de Robert II de Meulan et Marguerite, fille de Raoul de Fougères. Nous ignorons au juste quels étaient les liens qui unissaient la famille de Montreuil à celle de Meulan. A notre connaissance, Payen ne possédait pas d'autre terre en dehors de l'honor de Montreuil-l'Argillé.

Dans le conflit qui oppose Jean Sans Terre à Philippe Auguste, Payen de Montreuil opta pour le camp français, comme le comte d'Alençon et Pierre de Meulan, alors que Guillaume II de Saint-cénéri restait fidèle au roi d'Angleterre. En 
mai 1203, Jean Sans terre mande à son bailli, Jean de Préaux « d'obtenir pour Guillaume de Saint-Cénéri, la terre que Payen de Montreuil, qui est contre nous, tient dans le fief de Guillaume... » Ce fut le dernier acte "politique » des châtelains de Montreuil, désormais, le lignage va surtout s'occuper de ses possessions. La première charte que nous ait laissée la famille illustre bien ce changement. Entre 1197-98 et 1217, Payen de Montreuil, miles donne aux moines de Saint-Evroul la dîme de ses revenus et des droits de passage qu'il avait à Montreuil, ainsi que la dîme de Réville, reconnaît qu'il tient d'eux le patronage de l'église Saint-Léger avec le masuage et le bois situé à côté et abandonne ce qu'il avait ou réclamait sur les églises de la Goulafrière, Monnai, les Essarts et Ternant. Ce repli autour de Réville, sans doute accéléré par l'apparition d'un nouveau seigneur de Montreuil (Jean de Gaillon), se confirme à la génération suivante, Robert de Montreuil, fils de Payen se fait aussi appeler Robert de Réville. En 1220 il confirme les donations de son père puis donne plusieurs rentes à Saint-Evroul en 1222-23, et souscrit les chartes d'autres chevaliers voisins tels que Roger Goulafre, Guillaume du Tremblay, Ernaud de Saint-Martin, Jean des Haies. A partir de Pierre de Réville, fils de Robert, le lignage abandonne définitivement le nom de Montreuil. En 1261 il confirme les chartes de son père et de son grand-père. L'année suivante assigne à Saint-Evroul 24 sous de rente sur ces cens et Montreuil pour la quittance des services qu'il devait aux moines à cause de son manoir du bois de Réville ainsi que deux setiers et 9 boisseaux d'avoine par an que lui faisaient Raoul le Mounier, Roger Daniel et Richard de Noa et 3 mines de froment sur son moulin de Montreuil. La lignée des Réville s'éteignit avant 1339, date à laquelle un conflit oppose l'évêque de Lisieux à Etienne de Boscherville, seigneur de Réville à propos du patronage de l'église Saint-Léger.

Au total le lignage des Montreuil/Réville est significatif de l'évolution de la petite aristocratie. Probablement chargé de la garde du château de Montreuill'Argillé aux $\mathrm{XI}^{\mathrm{e}}$ et $\mathrm{XII}^{\mathrm{e}}$ siècles, il possède des revenus et des droits importants dans cette localité (moulins, cens, droits de passage...) et sur d'autres paroisses de l'honneur. Progressivement il abandonne une partie de ces prérogatives pour se consacrer avant tout à sa seigneurie de Réville dont il finit par adopter le nom (86).

\section{Bilan}

Ces quelques éléments permettent d'entrevoir ces mouvements qui affectèrent la petite aristocratie entre la fin du XII ${ }^{\mathrm{e}}$ et le début du XIV ${ }^{\mathrm{e}}$ siècle. A partir du dernier tiers du XII ${ }^{\mathfrak{c}}$ siècle les vassaux des Géré se parent du titre de dominus, émettent leurs chartes, certains prennent le nom de leur fief, d'autres peut-être érigent des habitats

(86) Sur les Montreuil Réville : Orderic Viral, op. cit., note 3, II, 36; II, 86-87; Pancarte du Bec., ed. Ch. Porée, Histoire de l'abbaye du Bec, Evreux, 1901, pp. 645-49; Cartulaire de Saint-Evroul, ${ }^{\circ s} 13$, 22, 181, 313, 358, 437, 439, 440, 452, 472, 607,608, 609, 885, 905: Cartulaire de la Trinité de

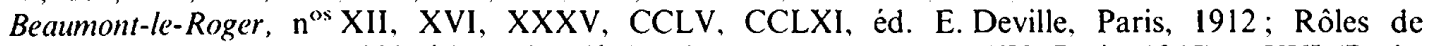
l'Echiquier, 1185, 1198, 1203, éd. Lechaudé d'Anisy, M.S.A.N., tomes XV (Paris, 1845) et XVI (Paris, 1852); A.D. Calvados, G 207. 
empruntant certains éléments au château. Un double mouvement d'émancipation des lignages vis-à-vis du châtelain et d'affirmation de leur présence sur les terres dont ils disposent semblent s'être mis en route. Il accompagne la progressive transformation du groupe aristocratique en une noblesse, processus qui paraît être achevé autour des années 1260-70 en Pays d'Ouche.

Au terme de cette étude sur les Géré il convient d'essayer de replacer le lignage dans l'aristocratie normande. Implantés en Normandie dans un contexte de renouvellement de la classe dirigeante normande autour de l'An Mil ; lignage en marche amené à tenir plusieurs châteaux dans le cadre de la dislocation de l'ancien pagus d'Hiémois et de la mainmise des Bellême sur la dorsale forestière s'étendant du perche au Mortinais ; pris entre plusieurs pouvoirs, ceux du duc de Normandie, du comte d'Anjou, de la maison de Bellême, des seigneurs de Mayenne, les Géré ne réussirent pas à s'implanter solidement sur les confins de la Normandie et du Maine. Somme toute, et quoiqu'en dise Orderic Vital, ils apparaissent comme un lignage de second ordre. Des châtelains certes, mais de moindre volée que les seigneurs de Bellême ou de Mayenne. C'est en définitive ce qui fait leur intérêt... 


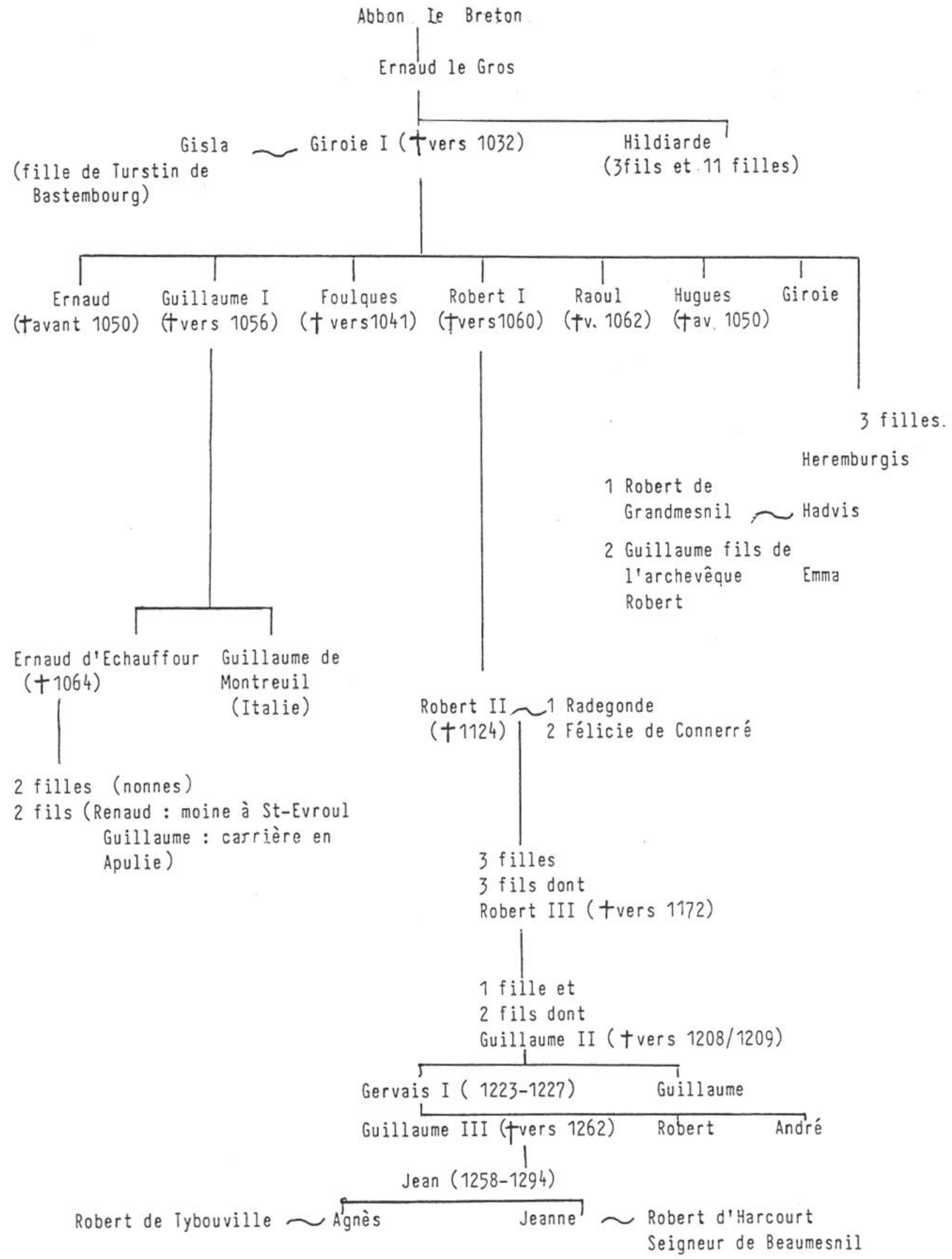

Fig. 1. - Généalogie simplifiée de la famille Géré. 


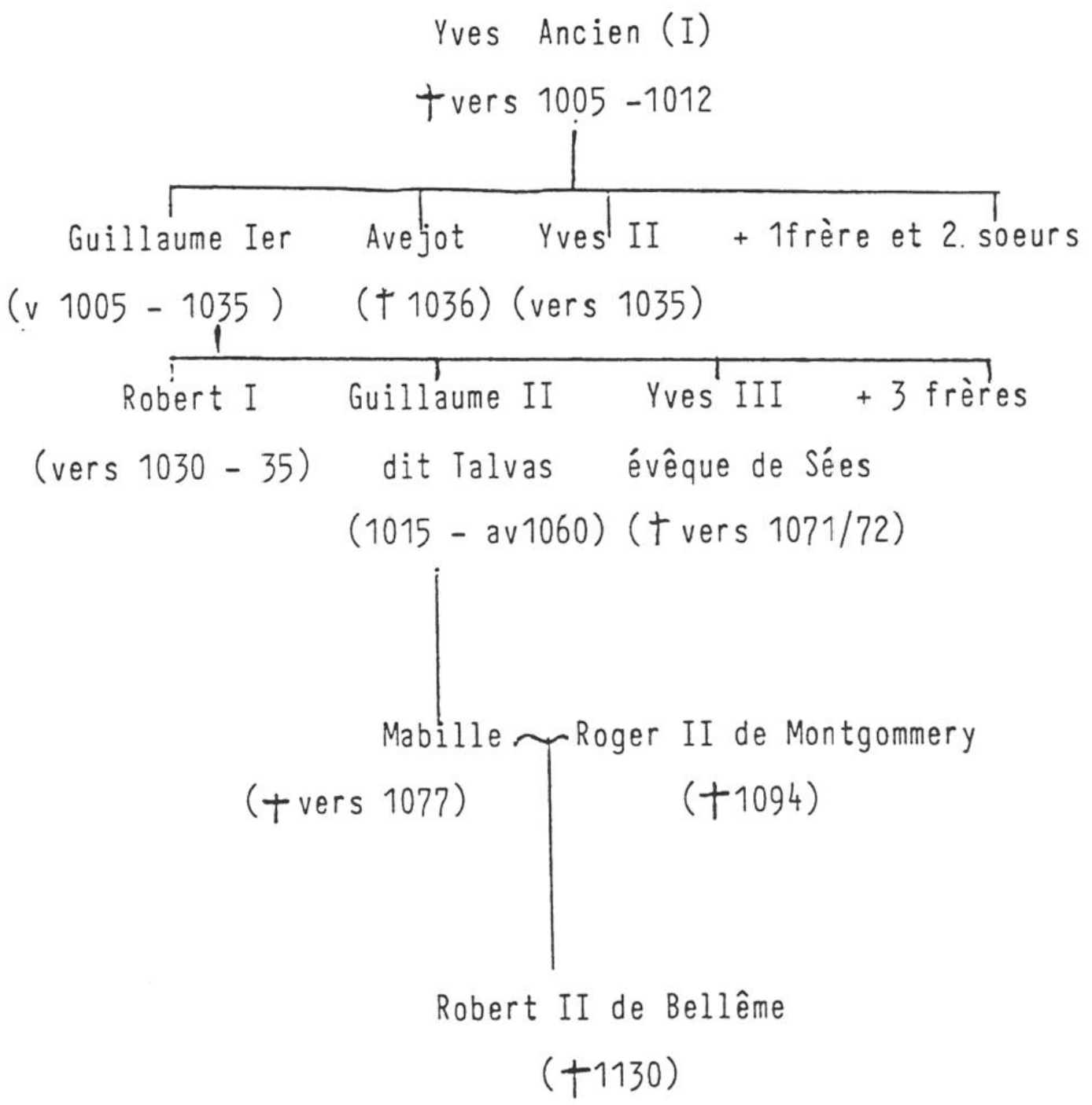

Fig. 2. - Généalogic simplifiée de la maison de Bellême. (Source: G. LouISE, op. cit., note 2). 


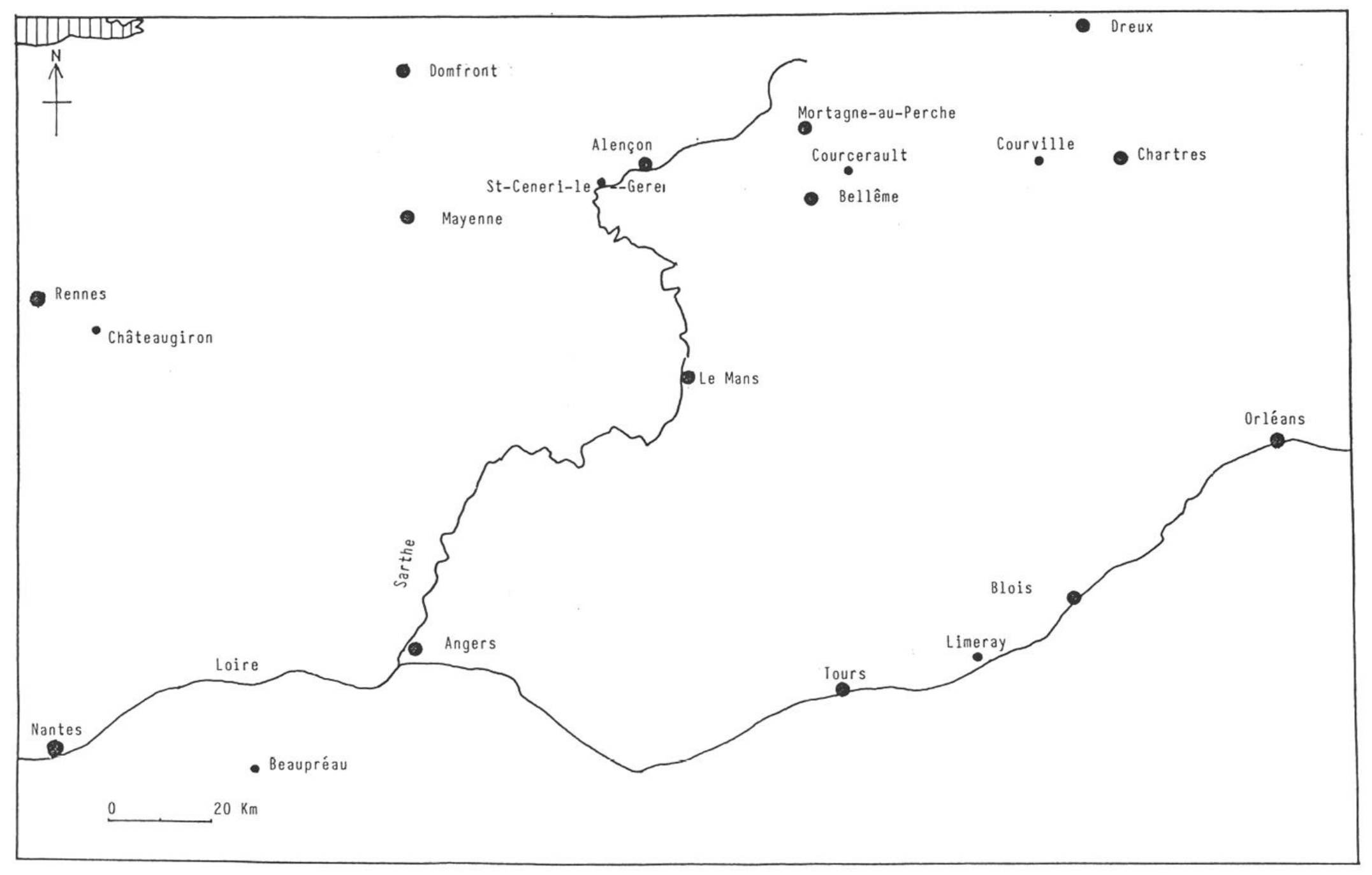

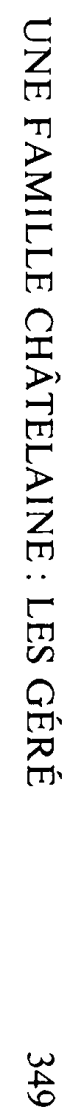

Fig. 3. Les origines du lignage, carte de situation. 


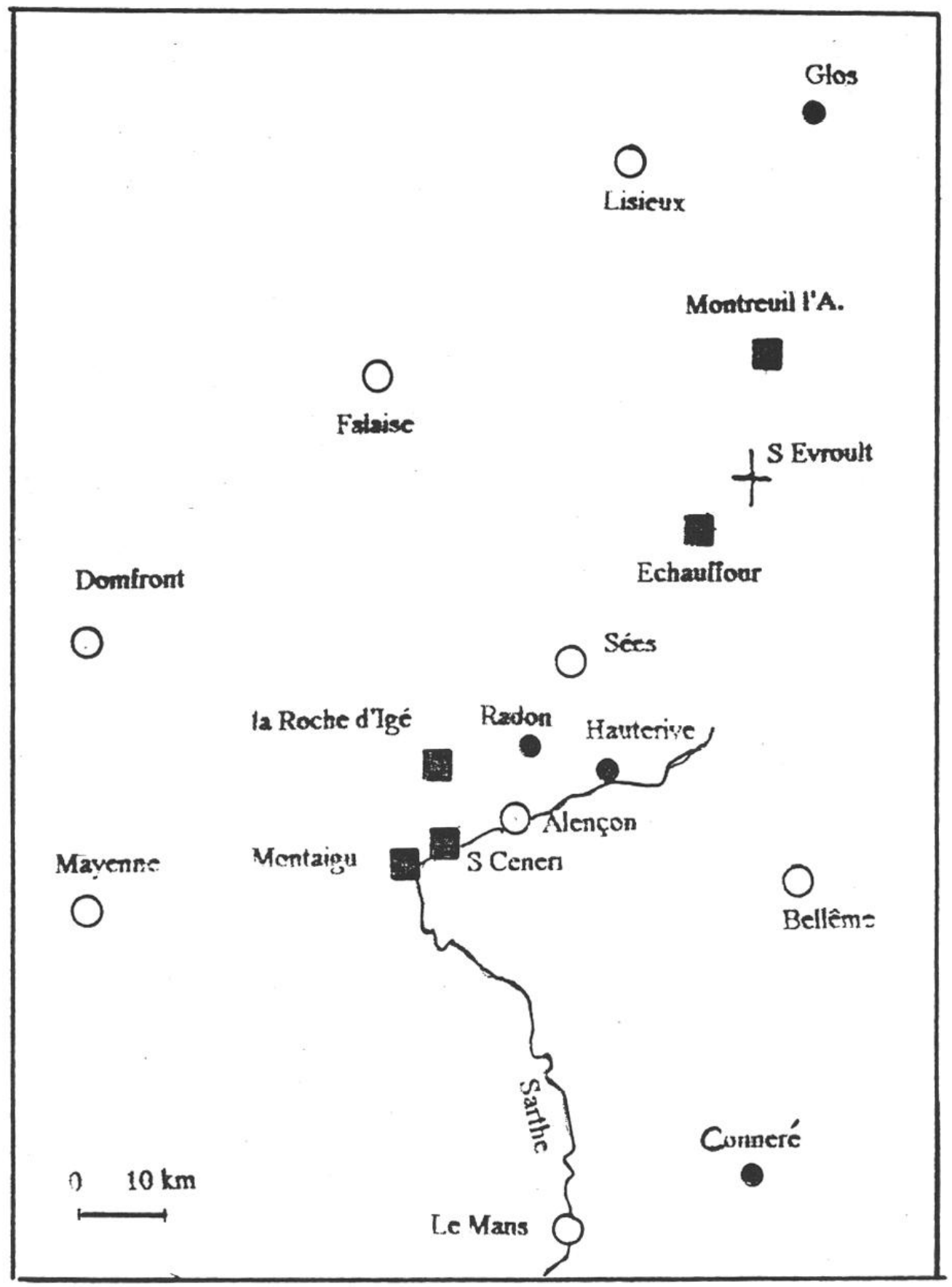

Fig. 4. - L'implantation du lignage au milieu du $\mathrm{XI}^{\mathrm{e}}$ siècle. 


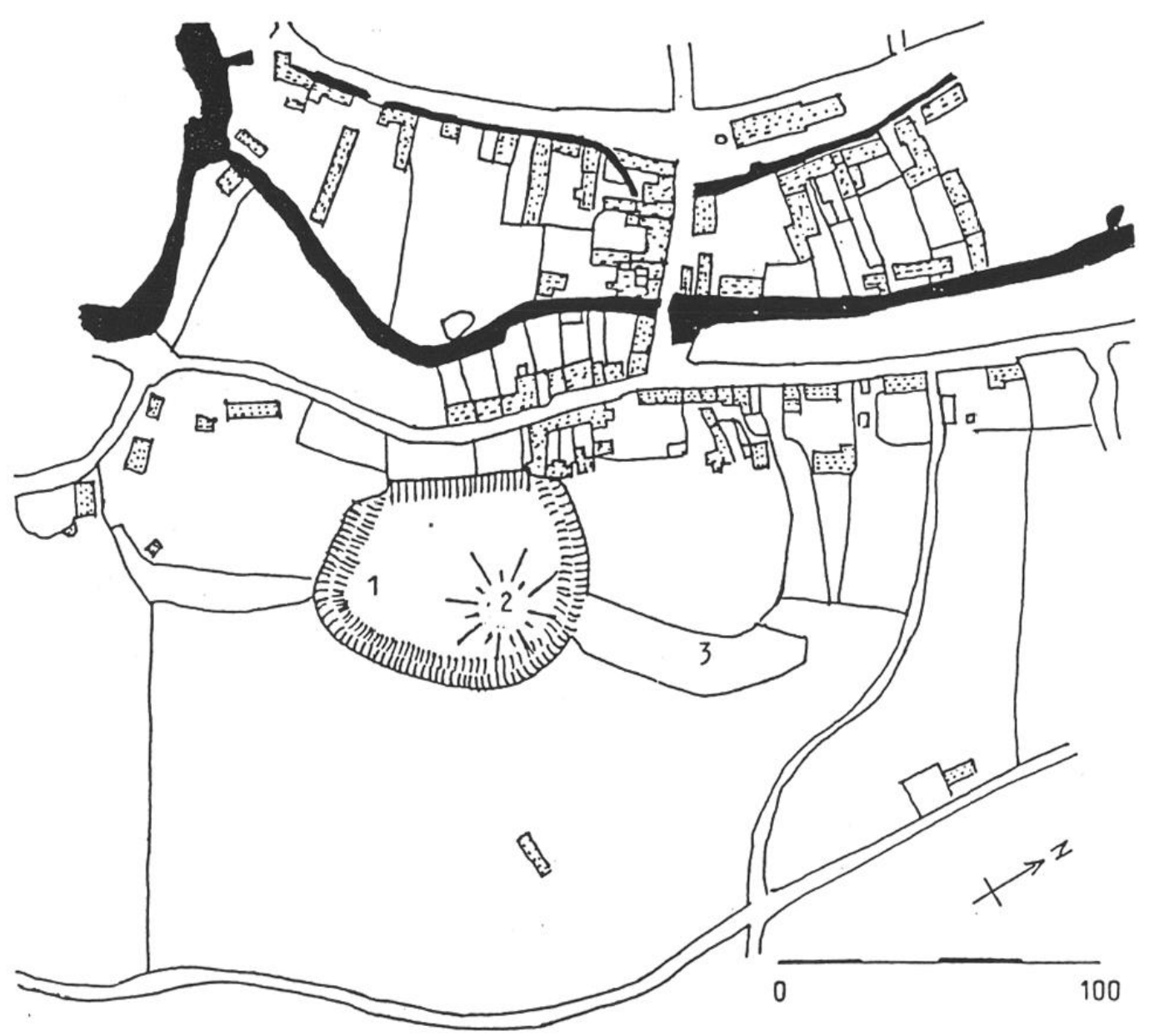

Fig. 5. - Le château de Montreuil-l'Argillé.

Sur le site appelé « le bourg ", on distingue, l'enceinte (1) pourvue d'une motte (2) et l'amorce d'une basse cour plus vaste (3) qui entourait peut-être le bourg castral. 


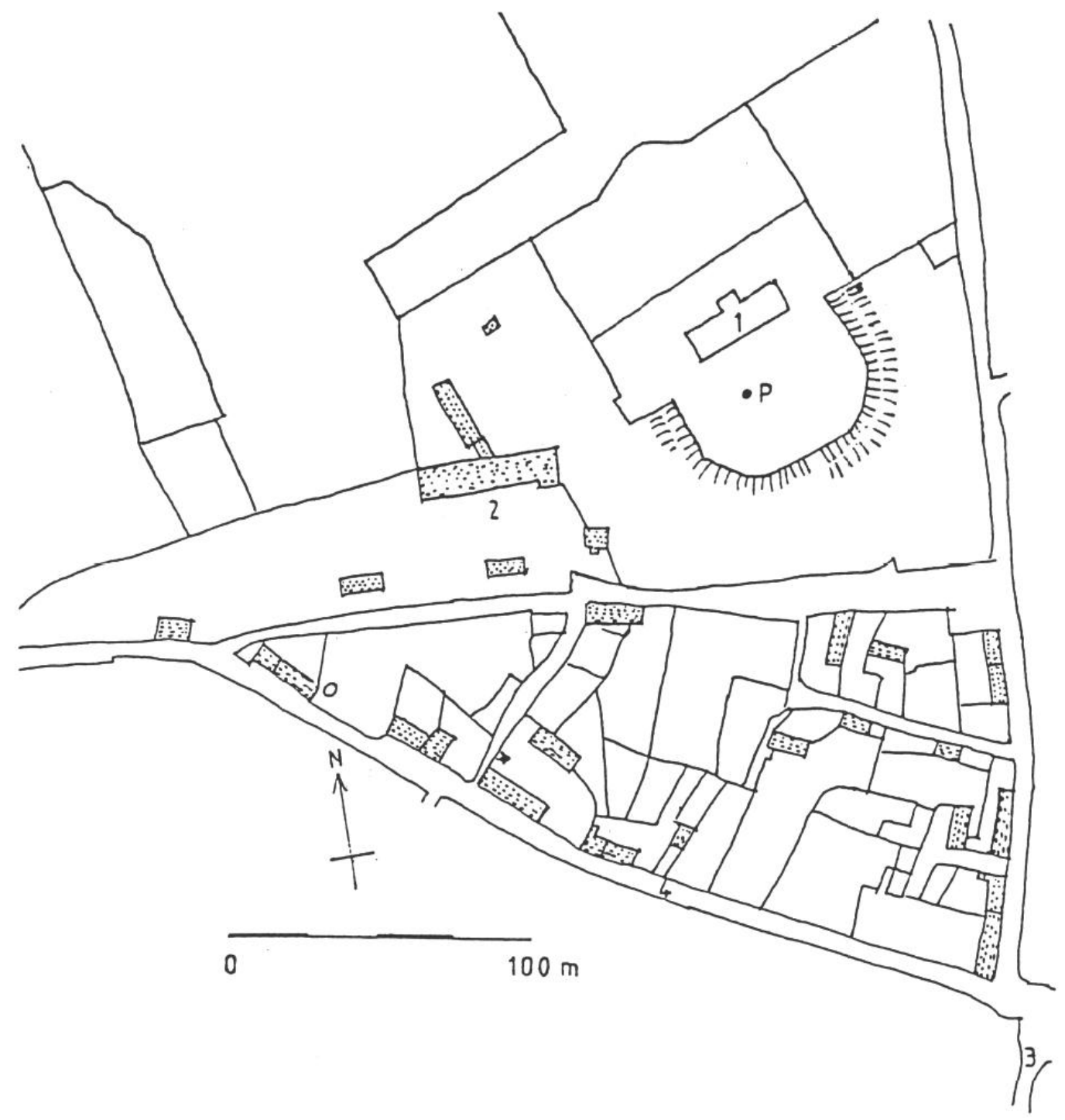

Fig. 6. - Le château d'Echauffour.

1) «Le château "; 2) "La ferme d'Echauffour », P = Puits ; 3) Chemin de Planches à Echauffour; 4) Route de L'Aigle à Sées. 


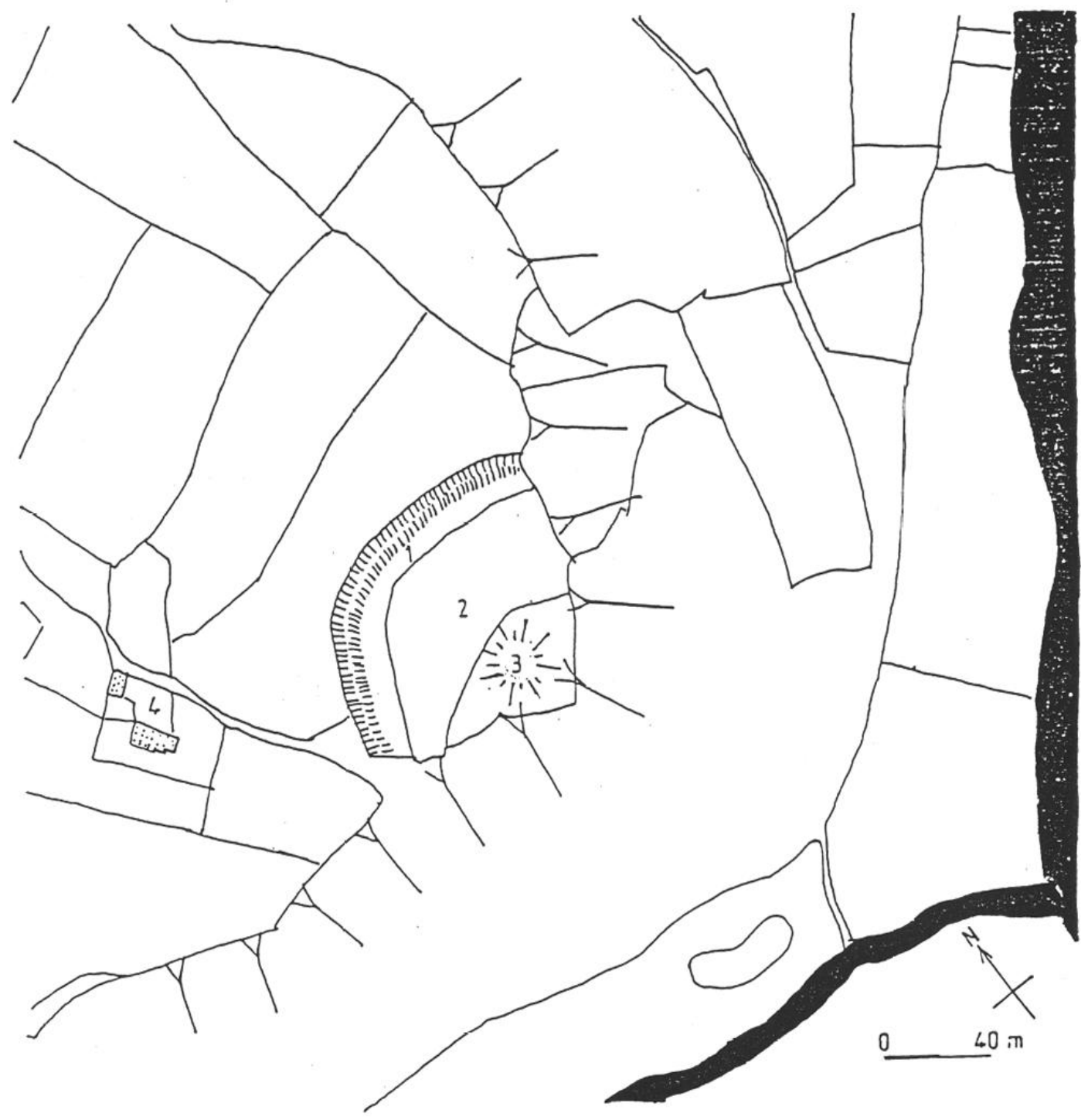

Fig. 7. - Le château de Montaigu.

MONTAIGU (commune de Saint-Pierre-des-Nids)

Toponymes : 1) La butte de la douve ; 2) La douve ; 3) Le château ; 4) Montaigu du bas (ferme). 


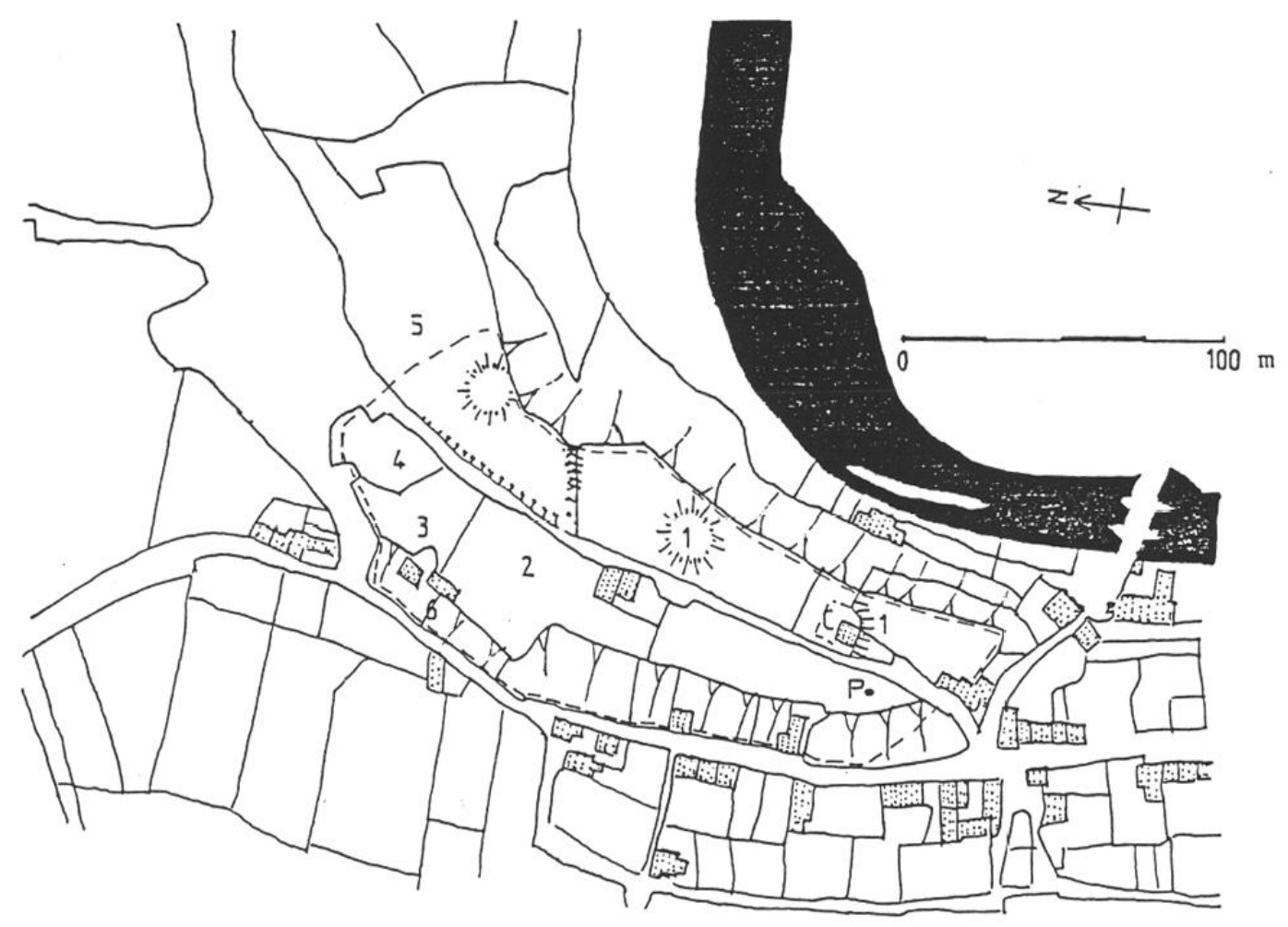

Fig. 8. - Le château de Saint-Céneri. SAINT-CENERI-LE-GEREI

Toponymes: 1) Le donjon ; 2) Le château ; 3) La butte du calvaire ; 4) Le calvaire ; 5) Le haut des vallées ; 6) La barre; P : Puits; C: Chapelle castrale.

-..---- tracé hypothétique de l'enceinte. 


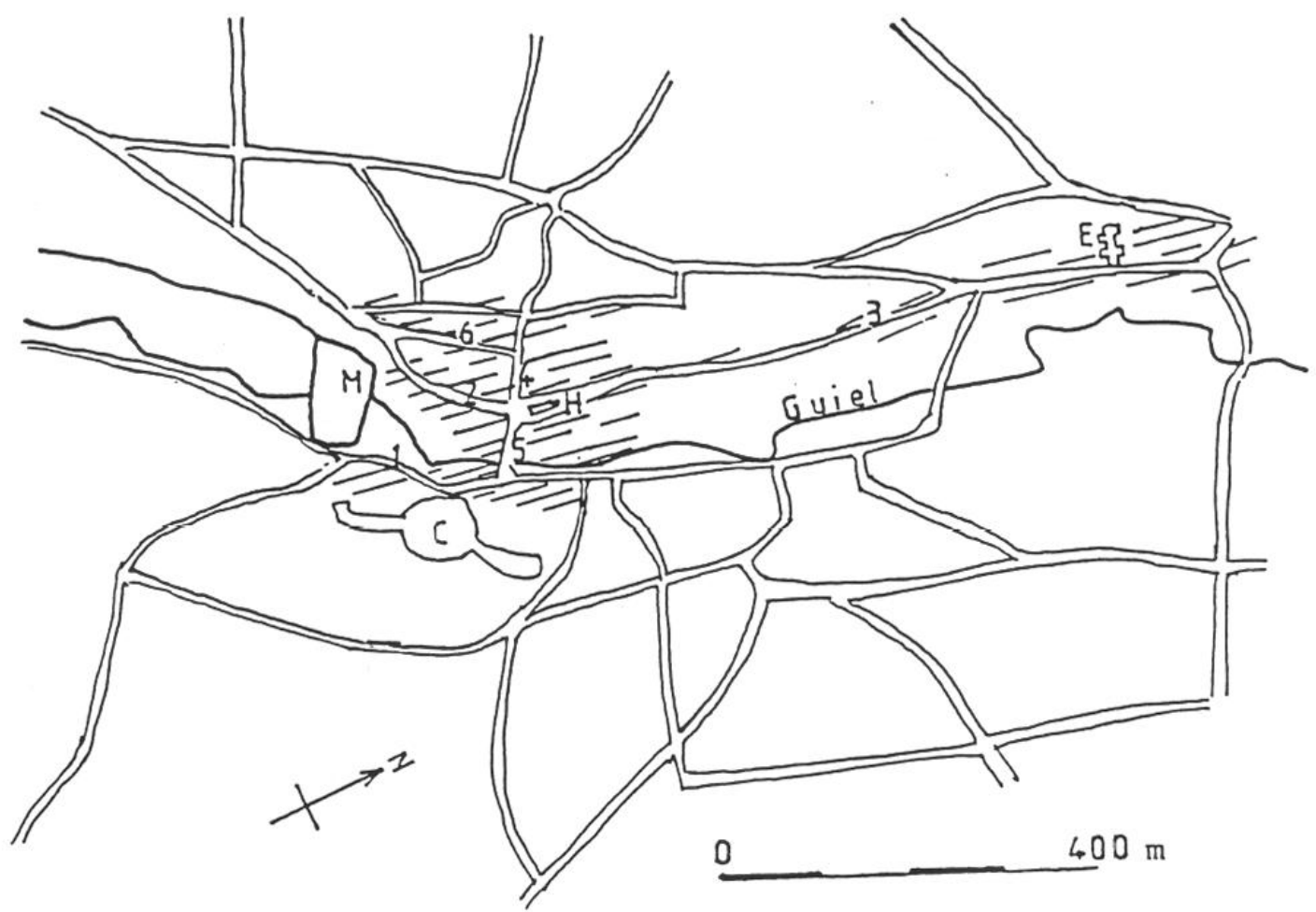

Fig. 9. - Le bourg de Montreuil-l'Argillé. LE BOURG DE MONTREUIL - L'ARGILLE

C : Château; E : Eglise ; H : Halles ; $\mathrm{M}$ : Moulin ;

1) Rue aux Anges ; 2) Rue Grande ; 3) Rue de l’Eglise ; 4) Rue Saint-Jacques ; 5) Rue du Pont ; 6) Rue aux Juifs. 


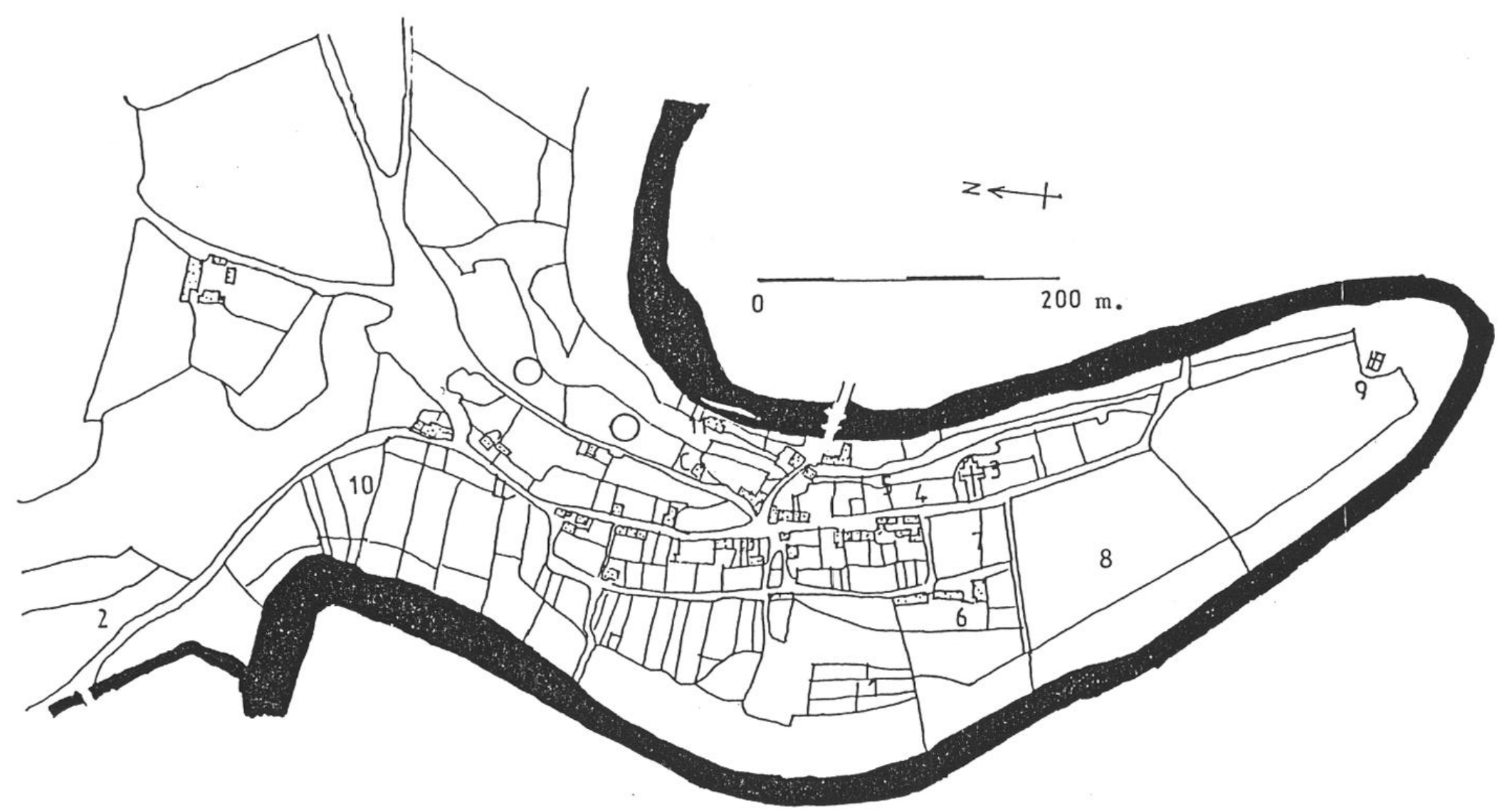

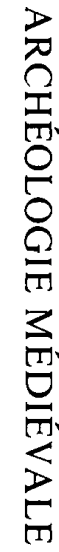

Fig. 10. - Le bourg de Saint-Céneri.

1) Les Cohues ; 2) La Noé de la Croix ; 3) Saint-Céneri ; 4) La Moinerie ; 5) Les Petits Cimetières ; 6) Le Presbytère ; 7) Le Clos de la Maison Dicu ; 8) Le Champ de la Maison Dieu; 9) Le Petit Saint-Céneri ; 10) Les Aires; 11) Le Moulin de Saint-Céneri ; C: Chapelle castrale. 